Archivum, LXXI, 2021, pp. 311-374

\title{
Versos ilustrados para memorias medievales: cuatro poemas inéditos Sobre el desembarco de Carlos I en España y su estancia en la casa-palacio de los Hevia en Villaviciosa (c. 1810). Estudio y edición
}

\author{
Rodrigo Olay VALDÉS ${ }^{1}$ \\ UNIVERSIDAD DE OvIEDo \\ olayrodrigo@uniovi.es \\ Álvaro Solano Fernández-Sordo ${ }^{2}$ \\ UNIVERSIDAD DE OVIEDO \\ solanoalvaro@uniovi.es
}

Recibido: 30/11/2020

Aceptado: 02/06/2021

1 Este trabajo ha sido posible gracias a una ayuda postdoctoral Juan de la Cierva-Formación (ref. ․ FJC2019-039000-I). Además, se enmarca en el proyecto de investigación SILEM II: Biografías y polémicas: hacia la institucionalización de la literatura y el autor (RTI2018-095664-B-C21) del Ministerio de Ciencia, Innovación y Universidades.

2 Miembro del proyecto de investigación "El ejercicio del poder: espacios, agentes y escrituras (siglos XI-XV)", clave HAR2017-84718-P, de la Universidad de Valladolid, financiado por el Ministerio de Economía, Industria y Competitividad de España, la Agencia Estatal de Investigación y el Fondo Europeo de Desarrollo Regional de la Unión Europea. 


\title{
RESUMEN:
}

En el presente trabajo ofrecemos la edición y estudio de cuatro poemas desconocidos Sobre el desembarco de Carlos I en España y su estancia en la casa-palacio de los Hevia en Villaviciosa. Los textos, ejemplo de poesía propagandística de la tesis que su título revela, conforman toda una secuencia poética que trasluce plenamente la mentalidad ilustrada en lo que atañe a una nueva concepción de la Historia y del valor fedatario de la documentación de archivo. De hecho, para probar el alojamiento de Carlos I en la Casa de Hevia, los poemas se plagan de referencias históricas, historiográficas y documentales, lo que hace de esta secuencia un llamativo ejemplo de historia versificada. En las siguientes páginas, como antesala a la edición de los poemas, se estudia su construcción y articulación poética, se establece su datación (c. 1810), se propone su posible autoría (Francisco de Paula Caveda y Solares), se identifican sus diferentes protagonistas históricos y se localizan sus ricas fuentes históricas y archivísticas.

PALA BRAS CLAVE: Poesía, historia, edición crítica, Ilustración, Carlos I, memoria familiar.

\section{Enlightened Verses for Medieval Memories: Four Unpublished Poems Sobre el desembarco de Carlos I en España y su estancia en la casa-palacio de los Hevia en Villaviciosa (c. 1810). Study and edition.}

\begin{abstract}
:
In the present work we offer the edition and study of four unknown poems On the landing of Carlos I in Spain and his stay in the Hevia house-palace in Villaviciosa. The texts are an example of propaganda poetry of the thesis that its title reveals and make up a whole poetic sequence that fully reveals the enlightened mentality with regard to a new conception of History and the probative value of Archive documentation. In fact, to prove Carlos I's accommodation in the House of Hevia, the poems are full of historical, historiographic and documentary references, which makes this sequence a striking example of versified history. In the following pages, as a prelude to the edition of the poems, their construction and poetic articulation are studied, their dating is established (c. 1810), their possible authorship is proposed (Francisco de Paula Caveda y Solares), their different historical protagonists are identified and its rich historical and archival sources are located.
\end{abstract}

KEYWORDS: Poetry, History, Critical edition, Enlightenment, Carlos I of Spain, family memory. 


\section{Planteamiento}

El 19 de septiembre de 1517 arribaba a las costas del concejo asturiano de Villaviciosa un joven Carlos de Gante que venía a ocupar el lugar que - en un itinerario histórico no exento de conflictos - se le reservaba en el trono y, en cierto modo, en la Historia. Puede decirse que ese proceloso viaje y el desembarco del que fuera el "último caballero medieval y primer monarca moderno" - como se le ha denominado frecuentemente ${ }^{3}-$, simbolizan perfectamente el accidentado abandono del Medievo hispano y la entrada en España de la Modernidad. Un acontecimiento que se encuentra fidedignamente documentado, prolijamente relatado y abundantemente estudiado ${ }^{4}$ y que, por más que puntual y anecdótico dentro de la retahíla de grandes transformaciones y procesos que esperaban a estos territorios durante el reinado del César Carlos, supondría un hito histórico a nivel local y especialmente para una de las familias de la zona que protagonizarían estos hechos: la de los Hevia.

Efectivamente, la casual llegada del entonces bisoño soberano iba a marcar un antes y un después para una parentela que, si bien venía décadas descollando como una pujante familia que buscaba hacerse un hueco entre la aristocracia y los poderes del Principado, con esta visita vería satisfechos en buena medida sus deseos de medra. Las noticias que algunos genealogistas posteriores proporcionan acerca de la familia Hevia la hacen partícipe

3 Aunque es un lugar común sobradamente repetido en la historiografía, quizá por lo literario de la semblanza que consigue, pueden señalarse las palabras que le dedica Salvador de Madariaga a Carlos de Gante definiendo así su personalidad $(1979,77)$.

4 Sobresale entre todos los testimonios sin duda el relato de un testigo presencial, esto es, la crónica escrita por Laurent Vital del viaje y primer año español del joven flamenco (Vital, 1992), así como los testimonios de Pierre Boissot, Pedro Mártir de Angleria, Francesillo de Zúñiga y otros cortesanos y embajadores extranjeros presentes en la travesía. A su análisis, junto a la documentación que dejó el acontecimiento y asumiendo los estudios que sobre este tema se han realizado, hemos dedicado algunos estudios previos (Solano Fernández-Sordo, 2017a y 2018). Asimismo, puede resultar ilustrativo consultar la aportación de Sánchez Pascual, 2018. 
de los episodios más antiguos de la historia medieval asturiana: según estas, se trata de una

ilustre casa asturiana, cuyo origen y antigüedad es tradición que dimana de uno de aquellos héroes que acompañaron al rey don Pelayo en sus primeras conquistas [...], que defendió contra los moros el paso del río Hevia, uno de los que circundan la montaña del Auseba, sobre la que se asienta Covadonga, y por este hecho sus descendientes comenzaron a llamarse Hevia, nombre que comunicaron a un lugar que fundaron y que hoy pertenece al Ayuntamiento de Siero (García Carraffa, 1932, 214-215),

haciendo a sus sucesores participantes también en otros importantes episodios bélicos, como la batalla de las Navas de Tolosa. Sin embargo, más allá de estas noticias legendarias, las primeras informaciones verdaderamente fidedignas de esta parentela proceden de la segunda mitad del siglo xv; y desde 1517 será su protagonismo inexcusable en la historia de Villaviciosa y del desembarco carolino, lo que una y otra vez aducirán las sucesivas generaciones de la familia como gran hazaña forjadora del linaje -o "inopinado / blasón que tuvo la casa / de alojar al rey don Carlos", como dice el texto que aquí presentamos (vv. 332-334)-.

Sin embargo, el devenir moderno y especialmente contemporáneo de la Casa de Hevia - cuyo tratamiento no es objeto del presente trabajo- hizo que, fruto de las herencias y las fusiones y divisiones genealógicas, en buena medida se perdiese el arraigo a la comarca villaviciosina e incluso su documentación se viese afectada. Afortunadamente, hace apenas diecinueve años el hallazgo casual y la donación de los restos del archivo de esta familia en el Palacio Familiar de Jove, en Gijón - linaje al que había acabado vinculado desde sus últimos señores a partir del siglo $\mathrm{XIX}-$, y su posterior donación pusieron a disposición de los investigadores esta colección bajo la rúbrica de “Fondo Jove Hevia" custodiado en el Archivo Municipal de Villaviciosa. 
Entre su abundante y valiosa documentación, se encuentra, con la signatura "Doc. 8.1" numerar, agavillados según el catálogo de la institución bajo el lema Relato de la estancia de Carlos V en la casa de los Hevia y desprovistos de toda indicación de autoría. En realidad, ni el cuaderno lleva título ni tampoco ninguno de los poemas que lo componen, que son cuatro; a saber: una octava real en su portada ("Ilustre y estimable monumento...", fol. 1r), un extenso romance a continuación ("Estando el señor Collar...", fols. 2r-12v), una serie de décimas —estas sí encabezadas por el rótulo "Décimas" - ("Mas, señor, la emulación...", fols. 12v-14v), $\mathrm{y}$, por fin, un "Ovillejo" de cierre, de nuevo titulado ("Carlos, Rey y Emperador", fol. 15r); tras ello, el resto de folios del legajo $(15 \mathrm{v}-16 \mathrm{v})$ están en blanco.

Importa destacar en primer lugar que estos cuatro poemas conforman una secuencia poética, pues se trata de diferentes partes de un mismo todo temático. Así lo prueba, sin ir más lejos, que la serie de décimas que siguen al extenso romance comiencen por la conjunción adversativa Mas ("Mas, señor, la emulación...", v. 413), pues en realidad prolongan, contrapuntean y responden a los versos que las preceden. De hecho, como el título del catálogo indica, los cuatro poemas se escriben con intención de defender y, es más, demostrar, incluso documentalmente, la estancia de Carlos I en la casa de Hevia durante su desembarco en Villaviciosa, en contra de las insidias lanzadas por enemigos o escépticos contra las pretensiones de la familia. No sería extraño que, en una población tan sumamente saturada de parentelas nobiliarias como es la Villaviciosa de la Modernidad, las luchas políticas y sociales por el dominio de la villa entre estas oligarquías - que conocemos sobradamente (Faya Díaz, 2003; Díaz Álvarez, 2012) - acarreasen el descrédito público o las acusaciones de falsedad respecto a las historias fundaciona-

5 Estando aún este fondo en proceso de catalogación, las signaturas que empleamos aquí siguen la numeración provisional. 
les de los linajes rivales ${ }^{6}$. De hecho, pudiera decirse que el anónimo informante maliayés de Tomás López para su Diccionario geográfico de España narraba con cierto escepticismo la anécdota del desembarco carolino y sus efectos en una época cercana a la confección de nuestra composición (Merinero y Barrientos, 1992: 290). En este contexto, la pieza que nos ocupa podría, por tanto, clasificarse como poesía propagandística, pues el autor de estos cuatro poemas los compone, y así lo confiesa, en defensa "de la casa de mi amo" (v. 396), que no puede ser sino la de los Hevia —a "mis amos" vuelve a referirse en el v. 464, en referencia de nuevo a las mismas personas-.

Así pues, en el presente trabajo nos proponemos estudiar y editar estos cuatro poemas por vez primera, poniendo de manifiesto su elaborada articulación. En primer lugar, nos referiremos a la estructura, datación y posible autoría de los poemas; después, en segundo lugar, trazaremos su dramatis personae, pues todos los muy abundantes personajes citados en la secuencia tienen base histórica, como documentaremos; y en tercer lugar nos detendremos en el rico empleo de fuentes históricas y documentales a lo largo de estos poemas, pues, en su deseo de hacer patente e incontrovertible que Carlos I sí se alojó en la mencionada casa maliayesa, el anónimo poeta movilizará una llamativa miríada de recursos y datos, que a continuación iremos desgranando y que convierten a esta secuencia poética en un documento histórico del mayor interés. Finalmente, ofreceremos la edición de los cuatro poemas de la secuencia.

6 Mucho es lo escrito acerca de esas creaciones literarias de genealogistas al servicio de intereses familiares que abonan esa miríada de árboles que constituyen ese bosque originario que se presenta como «selva de stemmata, de árboles genealógicos, y floresta de los cuentos maravillosos», en palabras de Jon Juaristi $(2000,9)$. 


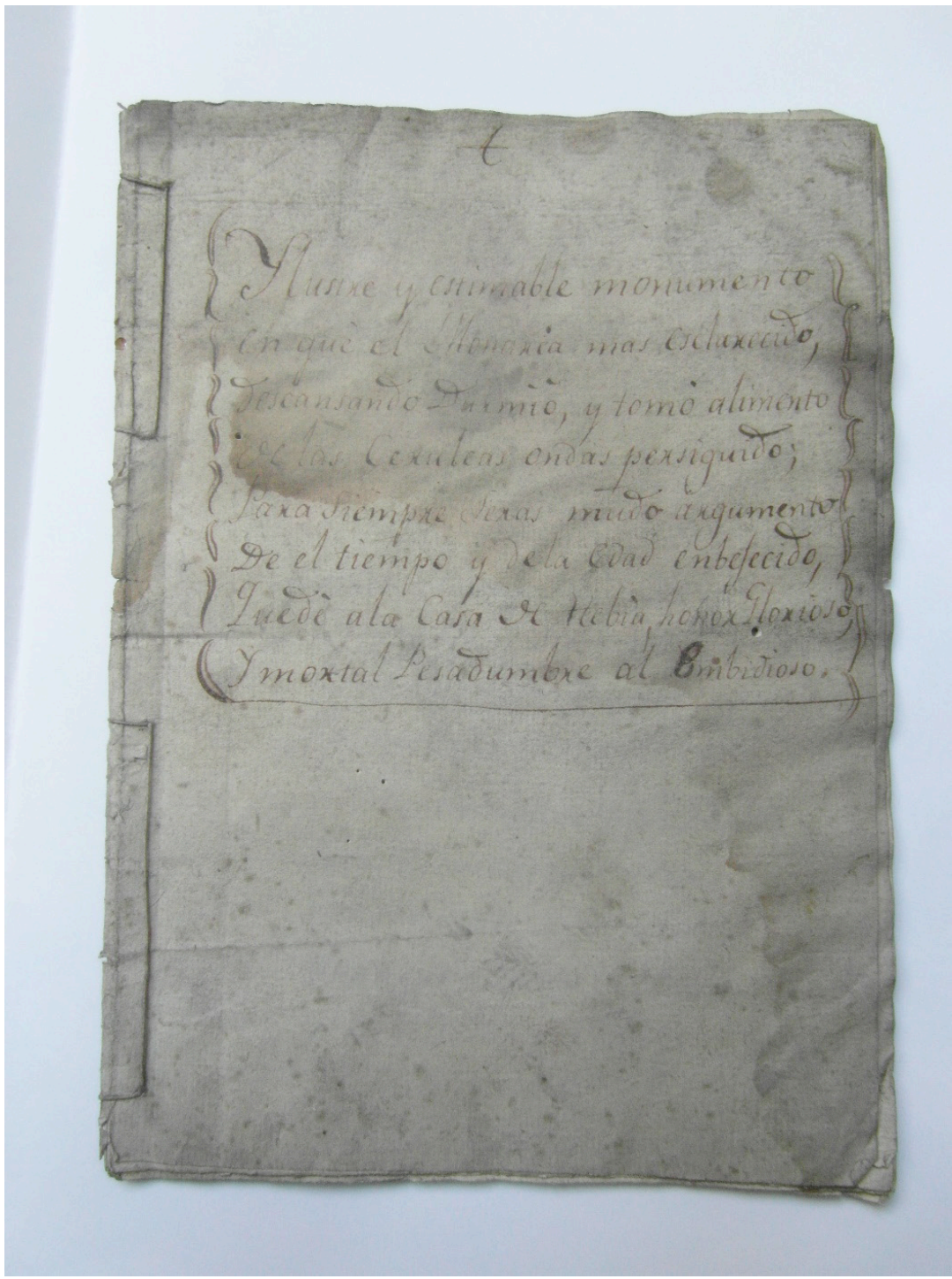

Archivo Municipal de Villaviciosa, Fondo Jove Hevia, doc. 8.1 (fol. 1r) 


\section{Los poemas: tema, estructura, datación, autoría.}

Como decimos, en este trabajo nos proponemos publicar y estudiar por vez primera la secuencia poética conformada por una octava real de apertura (8 vv.), un romance octosílabo (rima en -ao) de 416 vv., una serie de nueve décimas espinelas (90 vv.) $\mathrm{y}$ un ovillejo final, como cierre y conclusión (8 vv.). Como advertíamos, la unidad temática es evidente, pues todas las piezas conforman un todo encaminado a acreditar la estancia del rey Carlos I en la casa de los Hevia durante su desembarco en Asturias - sobremanera en el romance central de la secuencia- y desautorizar a los escépticos con dicho relato - principalmente en las nueve décimas-.

Pasando ahora a la estructura de la secuencia, cabe advertir que, si la octava real que la abre tiene una función principalmente introductoria, pues a fin de cuentas busca plantear la tesis que se tratará —si bien no olvida precisar que está escrita frente al "envidioso" (v. 8) que descree de la estancia de Carlos I-, el romance refiere con todo lujo de detalles el relato que la casa de Hevia sostiene de los hechos. Tras ello, las nueve décimas se dirigen a quienes pese a las referidas pruebas siguen dudando del hospedaje de Carlos I en la casa familiar; el ataque a los enemigos de la casa es ahora frontal y contundente, lo que aleja el tono de las décimas del más erudito del romance, asaeteado de referencias a numerosas fuentes. El ovillejo final, como la octava del principio —nótese que ambas son composiciones de ocho versos- busca cerrar de manera elegante y simétrica la secuencia, abundando en las ideas de fondo.

De tal manera, la parte del león de la serie que nos ocupa se la lleva, por extensión y vocación, el romance, que será la pieza a cuyo estudio más espacio habremos de dedicar, por ser, además, la que más personajes históricos convoca y hace un uso más rico y complejo de las fuentes.

Más en detalle, el romance "Estando el señor Collar..." se abre, tras una sucinta intervención del narrador, mediante un diálogo entre dos personajes que sirven como excusa para pro- 
piciar el relato de los acontecimientos relativos al desembarco de Carlos I y su posterior hospedaje en la casa de Hevia. Tales personajes son el "Señor Collar" (vv. 1, 12), más o menos escéptico con la verdad de los hechos; y "Tomás" (vv. 2, 5) defensor de su autenticidad - y personaje de estamento inferior, a la luz del tratamiento, lo que acaso pretende reflejar la pregnancia de este suceso entre el pueblo, lo que arrastra interesadas y evidentes implicaciones interpretativas, pues pretende dibujar a la casa de Hevia como favorecida por la gente llana y envidiada por otras casas nobles-. Como se expondrá más adelante, creemos poder ofrecer una hipótesis sólida de identificación de ambos personajes en discusión como individuos ciertos en las décadas a caballo entre los siglos XVIII y xIX, pues, dicho en pocas palabras, ninguno de los personajes que comparecen en la secuencia poética parece ser ficticio, de modo que no debemos olvidar que nos encontramos casi ante un memorial histórico versificado.

Más allá de esto, disponer una situación en que dos personajes no demasiado letrados se encuentren y den desarrollo mediante su diálogo a un tema de relevancia política es uno de los recursos más frecuentes en la poesía asturiana del siglo xviII, aunque ha de precisarse que aquí se hace sin vocación humorística, a diferencia de otros ejemplos que podemos recordar: así sucede, de hecho, en poemas de Xosefa Xovellanos como Esequies de Carlos III, Proclamación de Carlos IV o Fiestes a Xovellanos (Busto, 1997, 135-147, 157-173) o en composiciones de Antón Balvidares tales como Diálogu de dos casinos, Romanzón d'un viaxe a Uviedu o Ll'intierru del callórigu Reguero (Busto, 2012, 149-169, 171-185, 187-206); y todo ello obviando la Relación de un aldeano de Xuan Fernández Porléi (Busto, 2011-2012, 29-40) o el Romance [de] dos enfermos, [...] consultando con un cirujano de aldea de Nicolás Torano de la Puerta (Busto, 2011-2012, 42-48), por detener aquí la serie.

En el romance que nos ocupa, Collar reclama una explicación sobre la veracidad del alojamiento de Carlos I en la casa de Hevia (vv. 18-24), lo que desencadena un largo parlamento de Tomás 
sobre la cuestión, que alcanza hasta el final del poema (vv. 25416). Lo curioso es que dentro del relato de Tomás se introduce en estilo directo la declaración de un innominado "gran literato / y dopto en antigüedades" (vv. 46-47), además de "erudito y sabio" (v. 62), quien, tras registrar el archivo de la Casa de Hevia (v. 56), refiere los acontecimientos principales de la llegada de Carlos I a Villaviciosa y su estancia en dicha casa (vv. 65-261). Se trata de un recurso fundamental para justificar los muchos datos que se movilizarán, inverosímiles en boca de un lego como Tomás, pero no en la de este distinguido informante. Aunque mera conjetura fruto de la lectura del poema, creemos poder tener a este innominado "dopto" erudito (v. 47) por el "predicho don Miguel" (v. 289) más tarde aludido, dado que "Miguel" nunca antes es nombrado y la insistencia del verso en su condición de "predicho", coincidiendo en su labor pesquisadora (así se le dibuja en el v. 288), hace posible que sea el personaje presentado en la primera parte del romance.

Representado con un breve esquema, la estructura del romance sería la siguiente:

Narrador: vv. 1-18.

Intervención del señor Collar: vv. 18-24.

Primera parte de intervención directa de Tomás: vv. 25-64.

Relato del erudito "don Miguel" (dentro del parlamento de Tomás): vv. 65-261.

Segunda parte de intervención directa (histórico-documental y argumentativa) de Tomás: vv. 262-416.

No es, desde luego, una estructura demasiado perfecta, pues un cierre en cabal simetría del romance exigiría una breve intervención final de Collar dando por zanjado el asunto y algún tipo de conclusión del narrador; en todo caso, el romance ofrece sobrados elementos de interés por su densidad en referencias históricas y documentales y por la riqueza historiográfica de sus fuentes. 
Como hemos adelantado, el relato del romance halla su necesario complemento en las décimas que lo siguen, dirigidas directamente a lo que Feijoo llamaría "el lector no discreto y pío, sino ignorante y malicioso"; esto es, el hostil hacia la tesis defendida a lo largo de los poemas. Ciertamente, los compases finales del romance (vv. 402-416) ya se refieren a quienes puedan dudar de la veracidad de los hechos en él descritos, apostrofando a tales individuos de "escépticos", "arbolarios" ('botarates') y "pirrones extravagantes" — en elocuente referencia al filósofo griego- Continuando en esta línea, las nueve décimas espinelas que conforman el tercer poema de la secuencia se dirigen a contestar a quienes dudan de la estancia de Carlos I en la casa familiar, subrayando que su descreimiento procede de la envidia; pues son en realidad otras casas nobles las que buscan con estas insidias abajar el mérito de los Hevia. Ya latía este ataque en la sutileza de que fuera el señor Collar quien en el romance pidiera explicaciones sobre lo sucedido, pero en las décimas se verbaliza abiertamente:

Los soberbios y orgullosos

presumen que desmerecen cuando otros resplandecen 435 con títulos más gloriosos.

Por eso le son odiosos todos los sobresalientes en méritos eminentes y solo encuentran contento 440 en ajar su lucimiento por mil modos diferentes.

En suma, las décimas reprochan que "todos quieren subir / hasta el cielo su blasón" (vv. 415-416) a costa de desmerecer los méritos ajenos con "perversa intención" (v. 429). Con todo, reiterando el firme anclaje documental que atraviesa los poemas, "todo es bataola" (bataola, 'bulla, ruido'), pues, a la postre, "nadie 
iguala a Argensola" (vv. 449-450), que es la fuente más empleada en el poema y que, como veremos, verifica el desembarco de Carlos I en Villaviciosa. Todo lo cual, en definitiva, "prueba el lecho" (v. 459), esto es, el hecho de que el rey pernoctase en la casa de Hevia, diga lo que diga "el genio bilioso" que procura "obscurecer" lo sucedido.

Por fin, el ovillejo final —forma métrica de gran complejidad técnica (Domínguez Caparrós, 2016, 255)— loa a Carlos I ("Rey y Emperador"), al tiempo que subraya la tesis una y mil veces remachada a lo largo de la secuencia. Lo primero oculta una nueva sutileza discursiva: alabando al rey desde el prisma de la casa de Hevia, se insinúa que los escépticos con el relato de su hospedaje no manifiestan idéntico aprecio por el emperador. Lo segundo queda claro desde el momento en que leemos en el primer verso del ovillejo que "Gonzalo salió a alojarlos" (v. 492) y en los dos que cierran el poema y la secuencia al completo que:

descansó en la Casa de Hevia 500

Carlos, Rey y Emperador.

Representando esquemáticamente lo dicho hasta ahora, podemos resumir que la secuencia se articula del siguiente modo:

Octava real (8vv.): planteamiento de la tesis.

Romance (416 vv.): exposición históricamente documentada de los hechos, repleta de alusiones historiográficas y documentales.

Décimas $(90 \mathrm{vv}$.$) : descalificación de los escépticos con el relato$ anterior.

Ovillejo (8 vv.): planteamiento de la tesis y encomio de Carlos I.

Cambiando de tercio, en lo que respecta a la datación del poema, en el romance podemos leer que Sebastián de Navia, hijo del III marqués de Santa Cruz y a la sazón maestrescuela de la catedral de Santiago (vv. 31-32) visitó la casa de Hevia "habrá poco más o menos / cerca de cuarenta años" (vv. 29-30). En 
efecto, don Sebastián Alvaro de Navia Osorio y Roig de Magriña - "uno de los eclesiásticos más eruditos del siglo xvin", según Bellmunt y Canella (1894, I: 355) - fue realmente maestrescuela en la Catedral de Santiago, dignidad negociada por Carlos III en 1765 (Rojas Contreras, 1768: 268). En el archivo catedralicio compostelano se conserva documentación sobre él, en especial su testamento y codicilo, así como el inventario post mortem de sus bienes en 1783 y $1785^{7}$, respectivamente. Así pues, en el lapso de veinte años 1765-1785 hubo de tener lugar su viaje a Asturias y alojamiento en el palacio maliayés; esto es, sumando cuarenta años a estas fechas, podemos establecer los términos a quo y ad quem de 1805 y 1825.

Pero cabe acotar mucho más el momento de escritura de los textos, dado que la secuencia nos da noticia del propósito del viaje de Navia. Según el romance, el maestrescuela vino a Asturias buscando "un traslado / de cierto real privilegio / sobre el Voto de Santiago" en la Catedral de Oviedo (vv. 42-44). Si bien resulta imposible conocer si llegó a consultar alguno de los variados documentos relacionados con el llamado Privilegio de los Votos que se custodian -y custodiaban entonces - en el archivo catedralicio ovetense, sí podemos confirmar su presencia en Oviedo en torno a 1771 con el cometido de investigar acerca de ello, sin duda en el contexto del acalorado debate sobre ese asunto y sus implicaciones en la época moderna y especialmente a finales del siglo XviII. Dicho año don Sebastián incoaba en Oviedo un expediente ante el Juez Noble del Principado sobre el asunto,

7 Dentro de los registros del notario compostelano Luis Antonio de Turnes (Archivo de la Catedral de Santiago de Compostela, P 215/6 fols. 41r-42v, 57r-58r y 59r-97r)

8 Vid. al respecto Rey Castelao, 1985. Como mera hipótesis debido a la coincidencia de fechas, el viaje archivístico de Sebastián de Navia pudo producirse a raíz de la Representación contra el pretendido Voto de Santiago obra de Antonio Ponce de León (1771) en la que abundan los argumentos contrarios a la autenticidad del Voto basados en documentos e inscripciones de la catedral ovetense. Pudiera haber sido don Sebastián comisionado por el cabildo compostelano para comprobar las aseveraciones del Duque de Arcos in situ y contribuir a la refutación de su escrito. 
al que iba a vincularse un informe y reproducciones del artista Francisco Reiter sobre los motivos decorativos de las iglesias de San Miguel de Lillo y Santa María del Naranco, que podían interpretarse como testimonio iconográfico del voto y el llamado “Tributo de las cien doncellas" (Miguel Vigil, 1887, 231-232). Así pues, podemos asegurar que la visita del canónigo compostelano se produjo en esa fecha, lo que nos permite considerar los poemas compuestos alrededor de 1810.

En lo que a la autoría de la secuencia respecta, el original que manejamos no incluye ninguna información al respecto, ni tampoco consta el menor dato sobre el particular en el catálogo del fondo que acoge el poema, de modo que no nos cabe sino manejar prudentemente el texto como anónimo. No obstante, y siempre a modo de hipótesis, diferentes datos nos sirven para postular que en modo alguno sería descabellado ver a Francisco de Paula Caveda y Solares (1760-1811) como un posible autor de estos versos. En primer lugar, por razones cronológicas, pues cuadra perfectamente que esté escribiendo el texto en torno a 1810; en segundo lugar, por su origen y residencia villaviciosinos y por su parentesco directo con la casa de Hevia: no en vano, la casa de los Nava se encuentra a escasos metros de la de sus familiares; en tercer lugar, por su condición de poeta, pues lo sabemos autor del poema Jonatás, sobre el que mantuvo muy detallada correspondencia con Jovellanos (Caso González, 1984, 615-619); en cuarto lugar, por sus intereses históricos, patentes en estos poemas, ya que no en vano hemos de indicar que Caveda padre es autor de una Descripción geográfica e histórica del concejo de Villaviciosa; y, en último lugar, porque tanto en esta Descripción (Caveda y Solares, 1988, 83) como en sus materiales para el Diccionario de Martínez Marina (Friera Suárez, 2019, III, 1573) refiere el hospedaje del rey en la casa de Hevia y es, más aún, el único entre toda la abundante documentación conservada y la historiografía conocida que alude al beneficio de Santa Dorodia, que Carlos I habría concedido a la familia en pago por su hospitalidad. Solo Caveda y Solares y nuestra secuencia poé- 
tica (v. 261), en fin, aluden a este beneficio, lo que unido a estas otras concomitancias y afinidades nos sirven para proponerlo como verosímil responsable de estos textos.

\section{Dramatis personae.}

La vocación histórica del poema se advierte desde un principio en la quincena de personajes enumerados y en los muy abundantes acontecimientos protagonizados por ellos, tal como aquí sistematizamos, por orden de comparecencia:

- "Señor Collar" (v. 1): personaje que hace el papel de escéptico con respecto a lo que se contará, precisamente para desencadenar el relato. Pudiera tratarse de un simple personaje ficticio elaborado en beneficio del artificio literario, pero creemos poder ofrecer una conjetura sobre su identidad: rastreando la serie de padrones de moneda forera, censos y padrones de distinción de estados conservados para el concejo encontramos a partir de 1787 y hasta 1808 a cierto don Manuel Collar que aparece como "forastero" y relacionado con el estado noble como residente en la villa9. Tanto la propia coincidencia cronológica como el tratamiento de respeto que se le da - en el padrón figura como "don Manuel" y contándolo entre nobles e hidalgos notorios-, y especialmente su noción de forastero en tierra maliayesa hacen de él un perfecto candidato para identificarlo con el desconocedor de la anécdota carolina y escéptico ante ella, dispuesto a escuchar las explicaciones de Tomás.

- "Tomás" (v. 2): personaje popular - tanto en lo referente a su estamento levemente inferior como en una posición que revela el interés del suceso entre el pueblo-, en cuyo relato se injerirá la intervención del erudito que da las claves de la tesis del texto: el hospedaje de Carlos

9 Así se comprueba en los padrones de 1787 (Massin, 2012.4, 112), 1794 (6, 109), $1801(7,95)$ y $1808(8,61)$. Además, en el de 1801 aparece como apoderado de don Ramon de la Miyar ante el Señor Juez Noble $(7,95)$. 
I en la casa de Hevia. Siempre bien informado, aparece vinculado de algún modo - quizá contractualmente o siendo meramente admirador - a la familia, ya que, además de su presencia ante las consultas del archivo y la relación con uno de los antiguos señores, se presenta actuando como informante en un apeo de propiedades de la familia (vv. 276-280) o como representante de los vecinos para pagar la renta de Tazones (vv. 346-350) ${ }^{10}$. Esto hace de Tomás un personaje que se mueve entre el arquetipo del simple que da una lección al altanero y un verdadero erudito dispuesto a enseñar al ignorante mediante el testimonio de autoridad - la referencia al "dopto erudito" - , su propia experiencia documental su asistencia a registros y consultas del archivo, así como sus lecturas - y la propia lógica - el alegato final en contra de envidias negacionistas-.

$\mathrm{Al}$ igual que con el señor Collar, creemos que es posible proponer una identificación con un vecino conocido de la época que sirviera al autor para componer a su personaje, aunque aquí la hilazón es más débil debido a que contamos únicamente con un nombre propio (aunque no excesivamente común). Como en el caso anterior, en los padrones conservados entre 1787 y hasta 1808 se señala como hidalgo - y ascendiendo puestos en la listaa un individuo llamado "Thomás de Azebal" en las parroquias de Oles y San Martín del Mar, que se reparten el puerto de Tazones ${ }^{11}$. Carece de tratamiento de respeto pese a su condición hidalga, y nos hace plantear como hipótesis la identificación con nuestro "Tomás" el com-

10 Este mismo sistema de pago mediante comisión a un representante por parte de los diputados del Gremio de Tazones lo encontramos en 1812 gracias al cuaderno del cobrador de las rentas de la Casa (Archivo Municipal de Villaviciosa, Fondo Jove Hevia, carp.4, exp. 1, fol. 31r).

11 Así se comprueba en los padrones de 1787 (Massin, 2012.4, 61), 1794 (6, 67) y $1801(7,91)$. 
probar que este individuo es el único de este nombre que permanece durante estos años vinculado al puerto de Tazones, donde tiene lugar la conversación con el señor Collar.

- "Sebastián de Navia" (v. 31): personaje también real y documentado, hijo legítimo de Álvaro Antonio de Navia Osorio en su segundo matrimonio, que tuvo con doña María Teresa Roig Magriña (Navia Osorio y Castropol, 1975, 116). Nacido andaluz y criado en Siero, se formó en la Universidad de Salamanca como colegial mayor en el Real de San Bartolomé de Salamanca. Como ya se dijo, por favor regio alcanzó la dignidad de maestrescuela en la Catedral de Santiago en 1765, cargo que ostentó hasta su muerte en 1785 . A la sede apostólica hizo varios servicios, como sus investigaciones en defensa de la autenticidad del Privilegio de los Votos hacia 1771 - cuarenta años antes de la composición del poema-, cuando sus pasos debieron llevarle a Villaviciosa - desconocemos si por amistad o por qué otra causa, pues no tiene otra posible explicación recalar aquí en el camino de Santiago a Oviedo- en compañía de un segundo canónigo y un lector de letras antiguas que se hospedaron regaladamente en el palacio maliayés de los Hevia y leyeron por divertimento papeles de su archivo. Lo escuchado y aprendido por Tomás esa tarde, singularmente parecido a la prosa de Argensola, sirve al maliayés para ilustrar al señor Collar en su demanda y defender la indudable veracidad de la visita carolina.

- "Dopto" erudito (v. 47), quizá de nombre Miguel (v. 289): personaje introducido en el poema para hacer verosímil el documentado relato que al respecto se ofrece, así como parte de la detallada relación de documentación archivística aducida. Este conocedor de "antigüedades" y "caracteres ancianos" (vv. 47-48), del que nada más que su erudición se conoce, quizá sirva como recurso 
posiblemente ficticio que permite librar de la responsabilidad de sus asertos a un personaje indudablemente real y documentado como don Sebastián.

- "Monsiur de Jevres" (v. 212): se trata de quien el romance presenta como camarero mayor del rey y la Historia identifica como Guillermo de Croÿ, señor de Chièvres (1458-1521), en efecto con ese cargo. Se alude a una carta suya dirigida a Rodrigo de Hevia (vv. 295-297) como consecuencia de su hospedaje del rey y trasladándole el estado de salud de los jóvenes príncipes y del padre del chantre, quien supuestamente habría acompañado al cortejo regio. Tanto lo inverosímil de una relación de amistad trabada entre ambos en tan corta estancia, la condición de flamenco no hispanoparlante del camarero y su muerte al poco de los hechos relatados invitan a ver en ello una hipérbole prestigiadora de los Hevia más que una noticia verosímil.

- "Lasao" (vv. 212): gobernador de Castilla según el poema (vv. 212, 221), que se corresponde con Charles de Poupet, señor de la Chaulx (1460-1530), consejero de Estado y ulteriormente gobernador de Castilla.

- "Borrebat" (v. 213): Mayordomo Mayor del rey en el poema (vv. 213, 219-220), es Laurent de Gorrevod (¿1470?$1529)$, conde de Pont de Vaux y gobernador de Bresa.

- "Lanoy" (v. 213): Caballerizo Mayor de Carlos I (vv. 213, 217-218), identificable en la Historia con Charles de Lannoy, señor de Sanzeilles, Erquelines y Maingoval (14871527), primer Caballerizo Mayor de Carlos I (1515-1522), y posteriormente virrey de Nápoles (1522-1527).

- "Gonzalo / de Hevia" (vv. 244-245): sucesor de la Casa de Hevia y padre de Rodrigo, que decide acompañar más allá de Villaviciosa a la comitiva del rey - “a quien llevó el rey / de sus talentos prendado / y le mantuvo consigo / muy querido y estimado" - y fallece en Burgos (vv. 244249). Tal como resume el ovillejo final, fue él quien "salió 
a hospedar" (v. 492) a la comitiva, debiendo ser quien estaba esa mañana de septiembre de 1517 en el Torrexón de Tazones y asistió a la llegada regia, por lo que más adelante decidiría, en pago de su suerte, condonar parte de la renta a los tazoneros (vv. 333-346). Casado con Mencía González de Vigil, era hijo de Gonzalo Muñiz de Hevia y de Sancha Díaz del Busto - a través de quien se vinculaba a los Busto, una de las familias más importantes del concejo (Solano Fernández-Sordo, 2015a)-, no mintiendo Rodrigo de Hevia cuando asegure descender "de linages antiguos ansí de Hevia, Vegil, Bustio e otros" (Cavanilles, 1863, 143). En las décadas finales del siglo xv aparece junto a su mujer como propietario de varias casas en la villa de Villaviciosa (Uría Ríu, 2011, nn. 51-52). Apenas nada más se sabe sobre él, lo cual pudo ser aprovechado por el poeta-historiador para hacerlo "prenda del joven Carlos" por sus talentos y justificar así que acompañase a la caravana regia - hecho improbable dada la avanzada edad que debía tener, si no haber muerto ya para 1517-, ya que la historia y preminencia familiar comienza realmente con el chantre y el hospedaje carolino (Mallo Fernández-Ahúja, 2003, 142-144).

- "Rodrigo [de Hevia]" (v. 255): según el poema, el hijo de don Gonzalo, que obtuvo como consecuencia de hospedar al rey una chantría de la Catedral de Oviedo (v. 257) y los beneficios de Santa Dorodia y Graciolo (v. 261). En compensación por estas mercedes, paga un buey del tren de Carlos I (v. 266-269) y conserva la mesa y cuarto en que este comiera y se hospedara (vv. 270-272, 465).

Pese a estas referencias del poema, la Historia nos presenta un individuo algo diferente: nacido hacia 1460, aparece como un influyente hombre en la vida maliayesa en particular y asturiana en general como integrante de la élite regional a finales de la época medieval; de hecho, aparece ya como chantre de la Catedral de Oviedo 
—mucho antes del desembarco de Carlos I- al hacerse con la abadía comendataria de Valdediós y renunciar a ella a cambio de una pensión pontificia en $1492^{12}$. Desde entonces, su presencia menudea en las actas capitulares como miembro del cabildo de San Salvador de Oviedo, lo que revela su progresivo ascenso en los cargos e influencias de la institución, así como en la vida política de la ciudad de Oviedo: fue Provisor y vicario episcopal en varias ocasiones, se le nombró Alcalde Mayor de la obispalía a la muerte del prelado Valeriano Ordóñez de Villaquirán, fue procurador del cabildo ante el rey en varias ocasiones y el comisionado para tratar con el concejo ovetense las cuestiones referentes a la reconstrucción de la ciudad tras el incendio de la Navidad de 1521 y otros asuntos urbanísticos, se convirtió en persona de confianza del nuevo obispo Diego de Muros granjeándose los recelos de parte del capítulo y debiendo en ocasiones ser reprendido y disciplinado por ello; aunque ostentaría el lucrativo y prestigioso cargo de chantre catedralicio y disfrutaría de no pocos beneficios y rentas capitulares (Cuesta Fernández, y Díaz Caneja, 1958, 208-218. Uría Ríu, 2011, nn. 55-57). Ahora bien, justo los que nuestro poeta-historiador registra como donación de Carlos por sus servicios - Santa Dorodia y Graciolo - no los encontramos en ningún documento o referencia sobre el chantre, sino únicamente en las notas que Francisco Caveda y Solares añade a su informe sobre las parroquias maliayesas para Martínez Marina; y únicamente el primero (Friera Suárez, 2019, III, 1573).

Pero, además de este exquisito cuidado a sus influencias y propiedades, Rodrigo de Hevia fue afortunado con la visita de 1517, pues los servicios prestados al futuro Emperador le consiguieron la legitimación de su hijo natu-

12 Archivo General de Simancas, RGS, leg.149305, n.․ 317. Archivo Histórico Nacional, Clero, carp. 1613, no 22. 
ral y la licencia para fundar en él un mayorazgo - como acertadamente recoge el poema - que establece en 1529 y que está conformando hasta principios de la década de 1540, cuando debió de morir (Solano Fernández-Sordo, 2017b, 51-61 y docs. 17, 30-33).

- "Diego del Valle" (v. 283): se le figura haciendo un "gran registro" de la documentación del archivo de la casa de Hevia (v. 283). Nada podemos concretar de él, más allá de la sospecha de que pueda tratarse de una confusión con el siguiente.

- "Diego de Hevia” (v. 291): debe de tratarse, al ser contemporáneo a Tomás, de don Diego de Hevia Avilés y Flores, último señor con ese nombre de la Casa de Hevia. Falleció en mayo de 1758 habiendo muerto previamente su hijo, por lo que le sucedió su sobrino segundo, José Lorenzo de Hevia Bernardo (Miguel Vigil, 1892: 77-78; Solano Fernández-Sordo, 2017b: 70-71). Continuando la labor de su padre, tuvo, tal como el poema recoge, que hacer un registro del archivo a partir de 1707 para justificar su título y jurisdicciones ante la Corona a causa de la pesquisa de la Junta de Incorporación creada por Felipe $V$ con la intención de revisar los bienes y señoríos que estaban sustraídos o enajenados y podían estar usurpados (Giuliani, 1997), como ocurriera con otros muchos señoríos de Asturias, algunos de los cuales serán suprimidos, mientras que otros sí lograrán corroborar su existencia (Faya Díaz y Anes Fernández, 2007, 296-330). En todo caso, a esta labor de la Junta y de don Diego debemos en buena medida la conservación de parte de la documentación que hoy se conserva sobre los Hevia ${ }^{13}$.

- "Gutierre [de Hevia]" (v. 313): hijo de Rodrigo de Hevia, en quien se funda el mayorazgo. Elimina el poeta toda referencia a que Gutierre era hijo natural e ilegítimo al 21. 
ser fruto de la unión de un hombre ordenado - recordemos que Rodrigo era chantre- con mujer soltera. La regularización de Gutierre fue la primera gracia real tras la visita, apenas unos meses después de acaecida, en marzo de 1518: el ya rey Carlos I dice junto a su madre Juana que "por una nuestra cédula le lexitimamos" al hijo que don Rodrigo "hubistes e procreasteis en Elvira González de la Paraya" (Cavanilles, 1863: 142). Los reyes también concederán a don Rodrigo la posibilidad de establecer un suculento mayorazgo en su hijo legitimado. Erección que, como dice el romance y ya aclaramos, tiene lugar en 1529 y permite a don Gutierre titularse "mayorazgo y cabeza de la Casa de Hevia" como el primero de una línea que continuará hasta el momento de composición del poema.

- "Elvira / de Paraja" (vv. 315-316): madre de Gutierre de Hevia (v. 315) que, al momento de la maternidad, era "mujer soltera e no obligada a matrimonio" (Bellmunt y Canella, 1907, II, 119; Llano Roza de Ampudia, 1928, 148). Nada más puede decir la Historia o el poema sobre ella, pues no encontramos mención alguna sobre ella más allá de este solitario dato. 


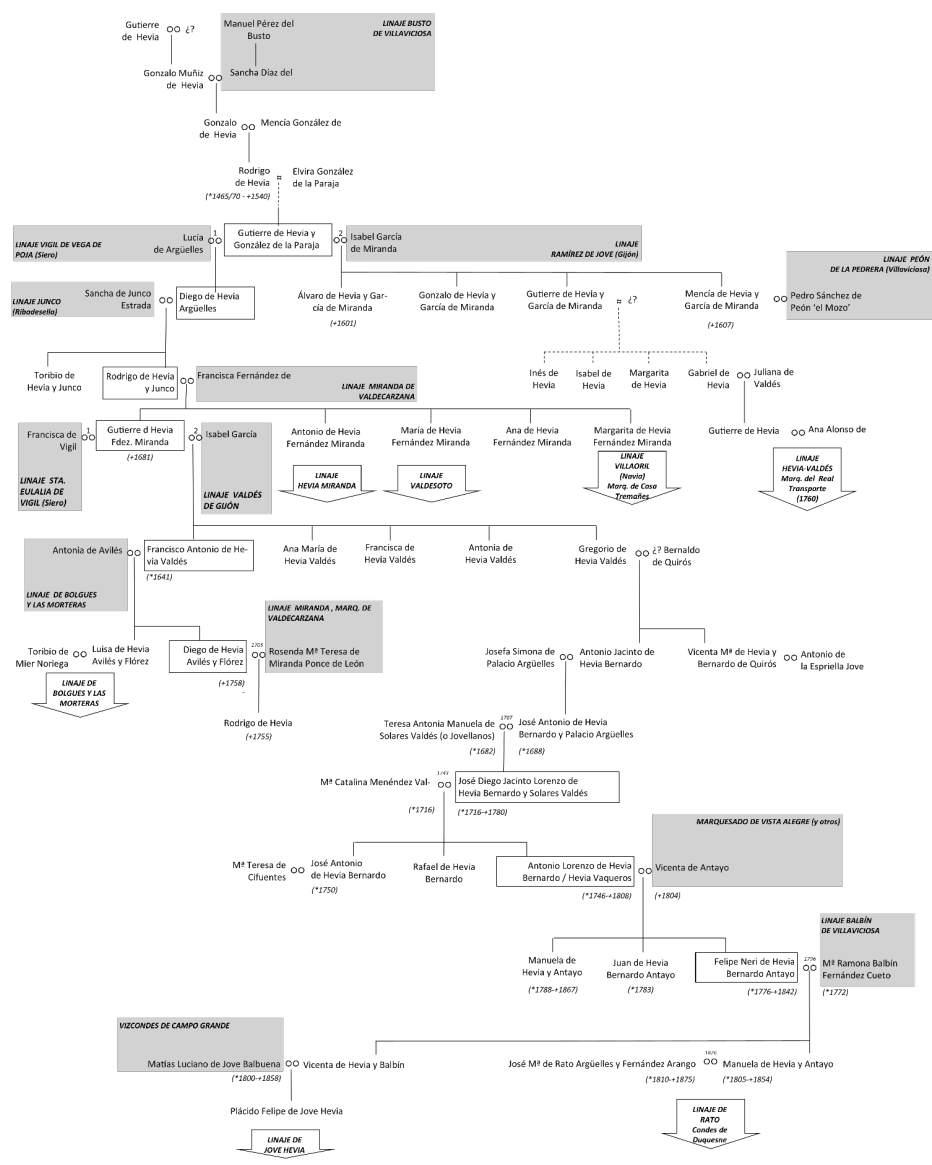

Árbol genealógico de la familia Hevia, así como sus conexiones con otros linajes (Solano Fernández-Sordo, 2017b: 78-79)

Finalmente, aunque no dentro de los personajes, es necesario hacer siquiera un breve comentario a los topoi que plantea el poema, pero no en su sentido metafórico de tópicos literarios, sino en su sentido literal de los lugares donde se desarrolla la escena. La acción primera del relato - esto es, la conversación 
entre el señor Collar y Tomás - tiene lugar ante una torre cuya antigüedad sorprende al primero y da origen al debate explicándole su contertulio que "aún era más anciano" el palacio de la villa (vv. 1-9). Aunque no se dice expresamente y no hay nada que permita asegurar una identificación del edificio, creemos por varios motivos que se trata del torreón que se levantaba sobre el puerto de Tazones: en primer lugar, se sitúa fuera de Villaviciosa al estar la casa "dentro" de ella (v. 9); asimismo, ha de tratarse de una propiedad de la familia Hevia, pues se compara con otra de la parentela —"aún era más anciano" — ; y, finalmente, la segunda y única otra mención a la torre en el poema la presenta como propiedad de don Gonzalo y la localiza más claramente -"estando / su torre tan inmediata / y al frente del desembarco" (vv. 357-364)-.

Sin duda entre todo el caserío tazonero debía destacar la Torre de los Hevia o Torrexón de Tazones, que se levantaba en el centro de la aldea a escasos metros de la línea de costa, junto al rollo y tendedero de redes. Derribada en 1883, se conoce su aspecto por descripciones y un dibujo de C. Balbín poco anterior a su demolición ${ }^{14}$ : era una torre fuerte, construida en piedra $\mathrm{y}$ sillares labrados con planta cuadrada y una altura de cuatro pisos. Sus destacados elementos defensivos - la parte superior almenada y con saeteras en las fachadas hacia el mar y el matacán de su pared septentrional - pareciera indicar un papel militar como atalaya costera, aunque el detalle de la ventana geminada con arcos apuntados y molduras situada a media altura parece

14 Vuelve a ser Caveda y Solares quien proporciona la descripción conocida: «en este mismo trozo, y ya en la Rivera, hay un torreón cuadrado de unas paredes muy sólidas mirando al mar con una de sus esquinas: está coronado en su parte superior de almenas con sus saeteras, y sólo tiene contra la población dos ventanas de arcos apuntados, separadas por una columnita. No sé con qué objeto se habrá edificado en un paraje tan poco ventajoso para una defensa una mole tan informe. A uno de sus lados están los cabrestantes con que estos infelices habitantes arrastran desde la orilla sus lanchas, sobre un pedrero incómodo, para ponerlas a cubierto de la furia del mar» (Biblioteca de la Real Academia de la Historia, ms. 9/6037, fol. $103 v)$. 


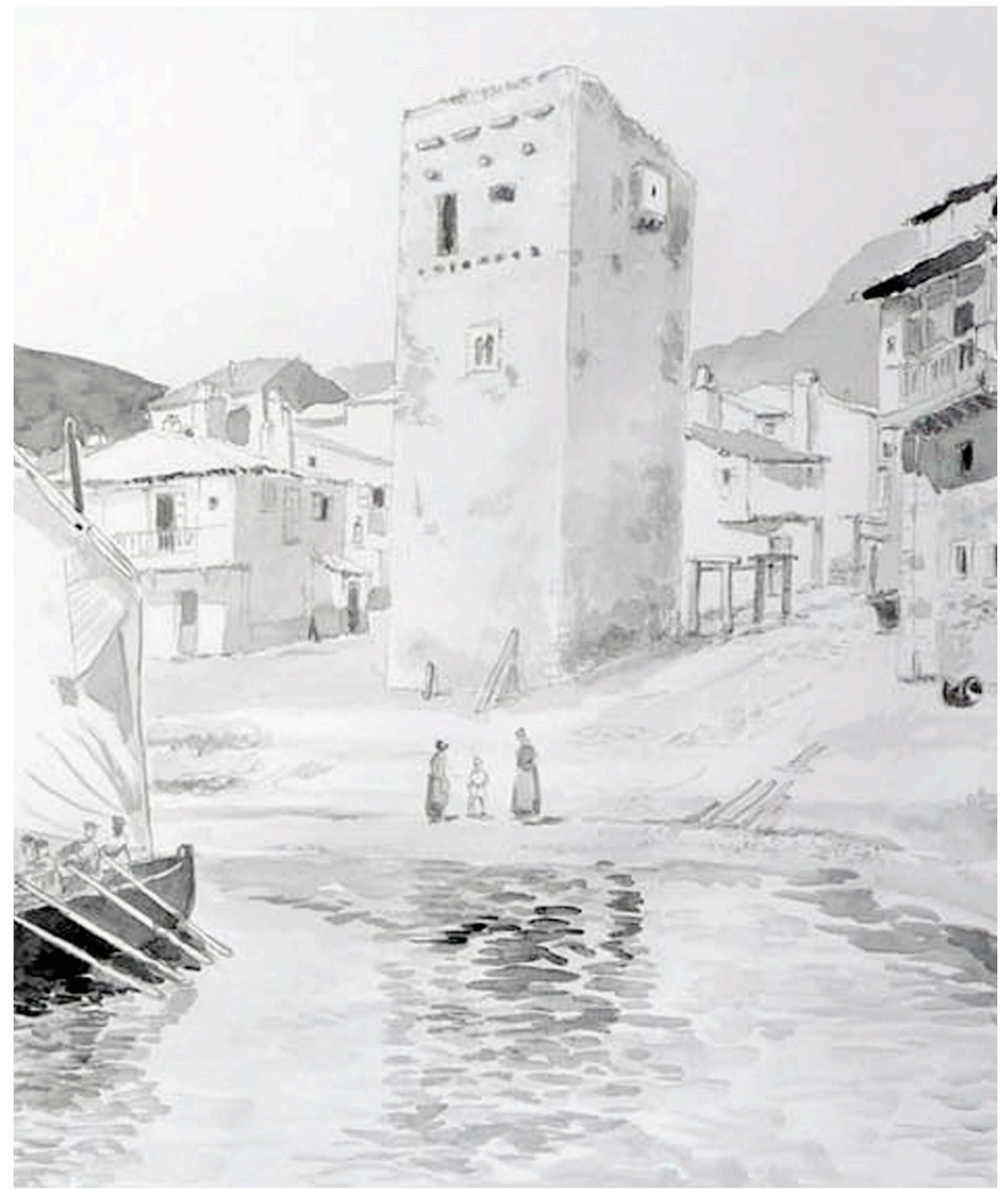

Reconstrucción de la Torre de Tazones y ensenada según el dibujo de C. Balbín y las descripciones de Caveda (Pedrayes Obaya, 1994, 50)

ser más propia de la arquitectura civil residencial de los últimos años del gótico en Asturias (Avello Álvarez, 1991, 203-204). En todo caso, ya fuera con una finalidad estratégica o de simple prestigio aristocrático, lo cierto es que la Torre de los Hevia se al- 
zaba destacando en el caserío de Tazones dominando el horizonte del pequeño puerto; limitado a la pequeña ensenada frente a la torre que empleaban los pescadores para arrastrar a tierra sus embarcaciones protegiéndolas de los embates del mar, aunque esta labor deteriorase mucho las barcas y fuese necesaria ante la falta de un buen fondeadero ${ }^{15}$.

Este lugar sería escenario de la arribada casual de la flota flamenca en 1517 y los momentos de confusión que generó, tal y como presenta nuestro poeta rememorando el acontecimiento. Algo que narra Tomás en su recuerdo cuando dice que de la torre "Gonzalo salió a alojarlos" (v. 492) y "se la ofreciese a su rey / en tan crítico embarazo / con su persona y hacienda / familiares y vasallos" (vv. 365-368).

Pero, a fin de cuentas, esa mañana de septiembre "no fueron allí a causa de que era un lugar demasiado malo para alojarse en él gente tan principal y a causa de que a unas dos leguas de allí había una buena villita donde estarían mucho mejor alojados que en el dicho Tazones", según Vital (1992: 154). Lo cual nos conduce al segundo escenario del poema, la casa-palacio que los Hevia tenían en la calle del Agua "dentro de Villaviciosa", "que eran aún más ancianos / el edificio y la casa / en donde estuvo hospedado" (vv. 6-9). Este complejo ocupa varias de las quadriellas fundacionales de la villa, dado que era un amplio conjunto residencial cerrado por una tapia con una huerta en su parte trasera donde se ubicaría su casa de servicio, así como al menos dos hórreos y una serie de árboles frutales, entre los que por su singularidad destacarían los naranjos (Uría Ríu, 2011: 87).

15 Así lo critica nuevamente Caveda a principios del siglo xIx: construyéndose un buen puerto en Tazones, «tendrían los naturales sus lanchas siempre en el mar, sin tener que arrastrarlas a tierra, cuya operación les gasta las quillas y las acaba a la mitad del tiempo que debieran durar. Tales consideraciones y los vienes que podrían seguirse a la humanidad de esta obra movieron a los vecinos ya en el siglo Xvi a formar un expediente para la construcción de un muelle» (Biblioteca de la Real Academia de la Historia, ms. 9/6037, fol. 102v). 


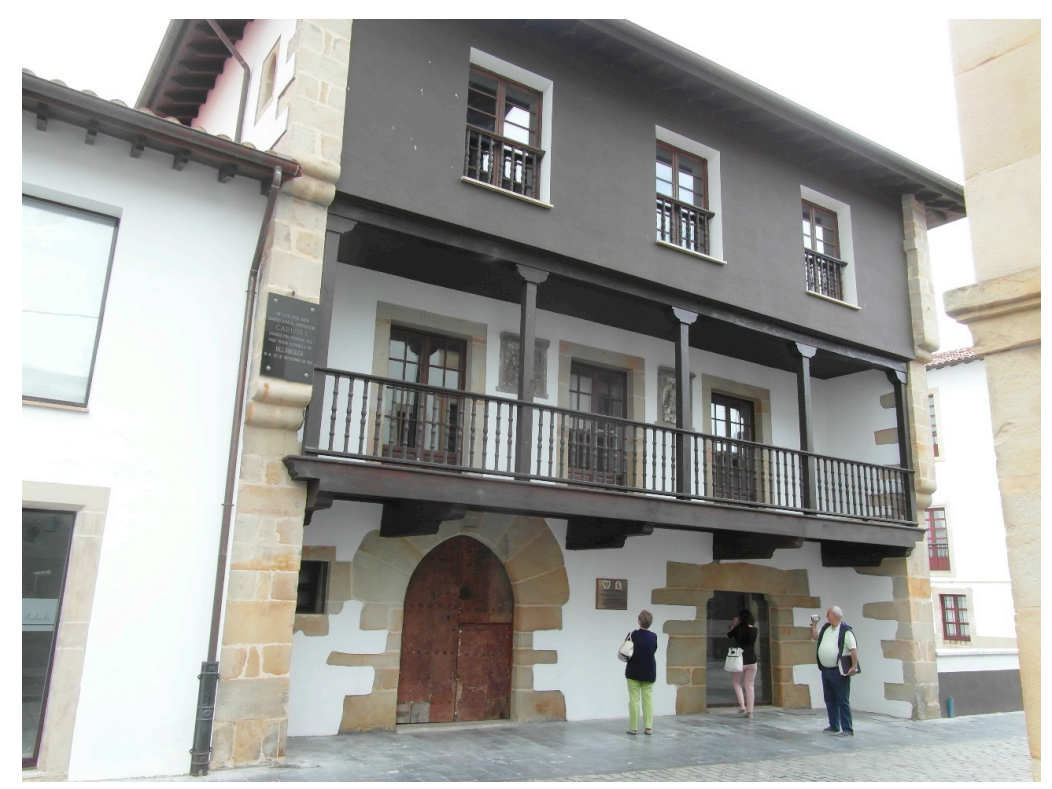

Casa-palacio de los Hevia en la calle del Agua de Villaviciosa, actualmente.

Por su parte, la casa es un edificio de planta cuadrada y tres alturas, claramente delimitadas en la fachada principal: planta baja a la que asoman dos portadas - con arco ojival, una, y cierre mixtilíneo, la otra-, abiertas a un porche o antoxana de poco fondo creado por los dos gruesos cortafuegos que encuadran la fachada; en el segundo piso un corredor de balaustrada de madera con tres vanos adintelados; y una última planta con tres ventanas alineadas con la línea de los cortafuegos. Culmina la composición un gran alero de madera. En su construcción se recurrió a la madera para el alero, las vigas interiores y los balcones, y sillar para la pared, mayor y de mejor talla en vanos y cortafuegos. Al interior poco se conserva hoy de la distribución original de la casa más allá de la escalera de piedra y parte del tabicado en madera de nogal de la última planta, donde 
se mantiene aún hoy la estancia donde según la tradición durmió el joven príncipe durante su visita. Es apenas un recinto de poco espacio y techado en madera, con una sobria decoración en molduras que según un informe del siglo xvir es un aposento "cerrado de tablas de madera y con muchas molduras en dichas tablas y la puerta a modo de arco con las mismas molduras y otras diferentes y el cielo de dicho aposento a modo de bóbeda con diferentes pinturas y dibujos, todo ello a la moda antigua" (Uría Ríu, 2011, 87).

Desgraciadamente, apenas nada de esa lujosa decoración ha llegado a nuestros días y el conjunto fue reformado tanto en el siglo xIx por la apertura de la carretera a Oviedo como más recientemente por su conversión en biblioteca municipal (Pedrayes Obaya, 1994, 131-134, 162-163; Mallo Fernández-Ahúja, 2003, 141-164). A fin de cuentas, mucho mejor que los protagonistas y los inmuebles testigos de los hechos, sobrevivió la historia de este acogimiento y su importancia en la memoria municipal y - especialmente - familiar, de lo cual es buena prueba la composición ilustrada que presentamos.

\section{Fuentes históricas y documentales}

Tal como hemos adelantado, la vocación proselitista de las composiciones tiene por consecuencia que constantemente se aduzcan fuentes históricas y documentales con el fin de probar que el rey Carlos I "descansó en la Casa de Hevia" y engrandeció con ello a esta familia. De tal modo, los cuatro poemas de la secuencia - mayoritariamente, el romance- se encuentran literalmente atravesados de referencias a otros textos que apoyan su visión de los hechos; a identificar y comentar estos materiales dedicaremos este apartado.

\subsection{Fuentes históricas}

La principal de las fuentes históricas manejadas por el romance nos es declarada por el propio texto: 
según lo dicen bien claro

los Anales de Aragón,

que yo mismo he registrado

y creo que está a los folios

cuatrocientos veinte y cuatro,

cuyo autor sigue a Zurita

y es Bartolomé Leonardo

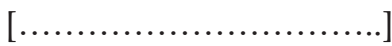

de Argensolo, prebendado

en Zaragoza y retor

de Villahermosa, nombrado

entonces para cronista

del rey y de sus estados

en el Reino de Aragón.

Como se echa de ver, el texto reconoce y explicita cuál es su fuente principal: a saber, los Anales de Aragón que prosigue los del secretario Gerónimo Zurita (1630), de Bartolomé Leonardo de Argensola (1562-1631) ${ }^{16}$. En este fragmento, además de declarar su fuente principal, el poema agavilla varios de los méritos fundamentales del menor de los Argensolas con el fin de encarecer la importancia y fiabilidad de sus escritos. Conocido sobre todo como poeta, Bartolomé Leonardo fue en efecto rector parroquial de los estados del duque de Villahermosa, su protector; a su muerte, pasó a ser, entre 1598 y 1603, capellán de la reina, cronista de Aragón desde 1615 y canónigo de la catedral de Zaragoza - " prebendado" — desde 1616 hasta su muerte (Blecua, 1974, IX-XIV).

Pero no acaban aquí las referencias a Argensola, pues en las decimas que siguen al romance podemos leer, alabando la fuente seguida y despreciando otras, que:

16 Respecto a los datos y el relato que hace Argensola del episodio, no resulta en absoluto discordante con los de otros testimonios empleados tradicionalmente para historiar el desembarco y estancia regia en Villaviciosa, tales como Laurent Vital o Boissot (vid. supra nota 2). Por esa razón, ya lo señalaban en paralelo Bellmunt y Canella (1907, II, 115). 
No creo ninguno de estos

que pretendan disputar

esta gloria singular;

445

$\mathrm{y}$, aunque con vanos pretextos,

dirán no estar manifiestos

los hechos en los autores

más clásicos y mejores.

Pero todo es bataola,

pues nadie iguala a Argensola

entre nuestros escritores.

Fue con tal ingenuidad

continuador de Zurita

que en cuanto escribe, acredita

grande amor a la verdad.

Aquesta sinceridad,

libre de todo cohecho,

de tal suerte prueba el lecho

que queda con su relato

460

(no siendo algún mentecato)

todo el mundo satisfecho.

Volviendo de nuevo al romance, a tanto llega su afán de exactitud que incluso precisa la página en que se encuentran los datos que le interesa reflejar ("y creo que está a los folios / cuatrocientos veinte y cuatro", vv. 229-230); y, de hecho, en la pág. $424 \mathrm{~b}$ de la primera edición de los Anales comienza el relato del viaje por mar de Carlos I desde Alemania a España, que es donde se abre así mismo la narración del romance que nos ocupa en su verso 65. 
$424 \quad$ Lib. I. de los Anales. M.D.XVil.

Rey, vifitó la Iglcfia de To- no nada propicio a fus ForIcdo, y los Monaterios de tunas. Mas el Rey,oponienMonjas,que alli, $y$ en Illeres dofe a todos losimpedimen Partefe el edificava $Y$ afegurado por tos, y a los vitimes parce: Tardenal,pa y cartas de fit Mageltad, de reccbiral que funavegacion tonia ya
Rey. cierto el plazo, tomò el camino para Alcalà de Henares, y de alli el de Aranda. - Avia el Rey confolado tame bien los Reynos difta Coro Avifo que el na, con cartas afectuofas a

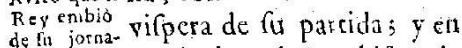
da a los Rey particular al Arçobifpo do nos de Ara- Caragoça fu tía. Pero toda
gon.

- via, con fer tan defigual aquella paz capiculada en Noyon, fue nccefario pafar por fu defigualdad, y que Tolera el nueftro Rey pidiefe al de Frä Aey la defir cia,prorrogacion del cumpli paz concluy miento que rcqueria cicrto da en Noyö. pacto de lla, para poder efe. Etuar fu pafaje. Contraponiá fe a efte fu defeo, las defrgual dades del Tiempo, y el pronoftico del Otoño, quelas amenaçava mayores, y los, no vulgarmente artificiofos confejos de los Privados del Rey, quele entretenian en Fhandes, remiendo (y no fu fundamento) algun accidente guardado en Efpana, res de que dilatafe la jor. nada, para mas cutera feguridad, fe embarcò luego con la Infanta Doña Leconor fu hermana. Salio de Middelburgh a XII. de Agofto det- Parrefect teaño M.D.XVII. y hazien pe pasalpa dofe a la vela, atraveró la $\mathrm{Ar}$ mada en fulcifma fazon, cl Occeano Britanico: $y$, en el de Aquitania, dexaron abilnieftro lado la Normandia, $y$ la menor Bretaña, alexalndofe mucho de todas las $\mathrm{Cof}$ tas de Francia Fue en todo lo natural,profpera fu navegacion, bien, que no le faitaron algunos contraltes. Afligio fumamcritc al Rey, el in- Incendio de cendio de un navio, donde uneravio, venia buen numero de firs dosdel Rey. cavallos, porque fe abrafaron con ellos al Teniente de Cavallerizo Mayor,vein te y dos Cavallcros, de cdad floreciente Pajes del Rey, y los criados dellosilos $M$ arineros y los Grumetes.A treze dias defpues deftamiferable Tragedia, fe les sparecio

(Argensola, 1630, 424)

Basta, pues, comparar el relato en verso del "dopto erudito" con la prosa de Argensola: los paralelismos saltan a la vista, pues 
la adaptación versificando al aragonés es literal en orden de los acontecimientos, anécdotas referidas y ecos léxicos. La asimilación es tal, que nos parece bastante elocuente yuxtaponer ambos textos:

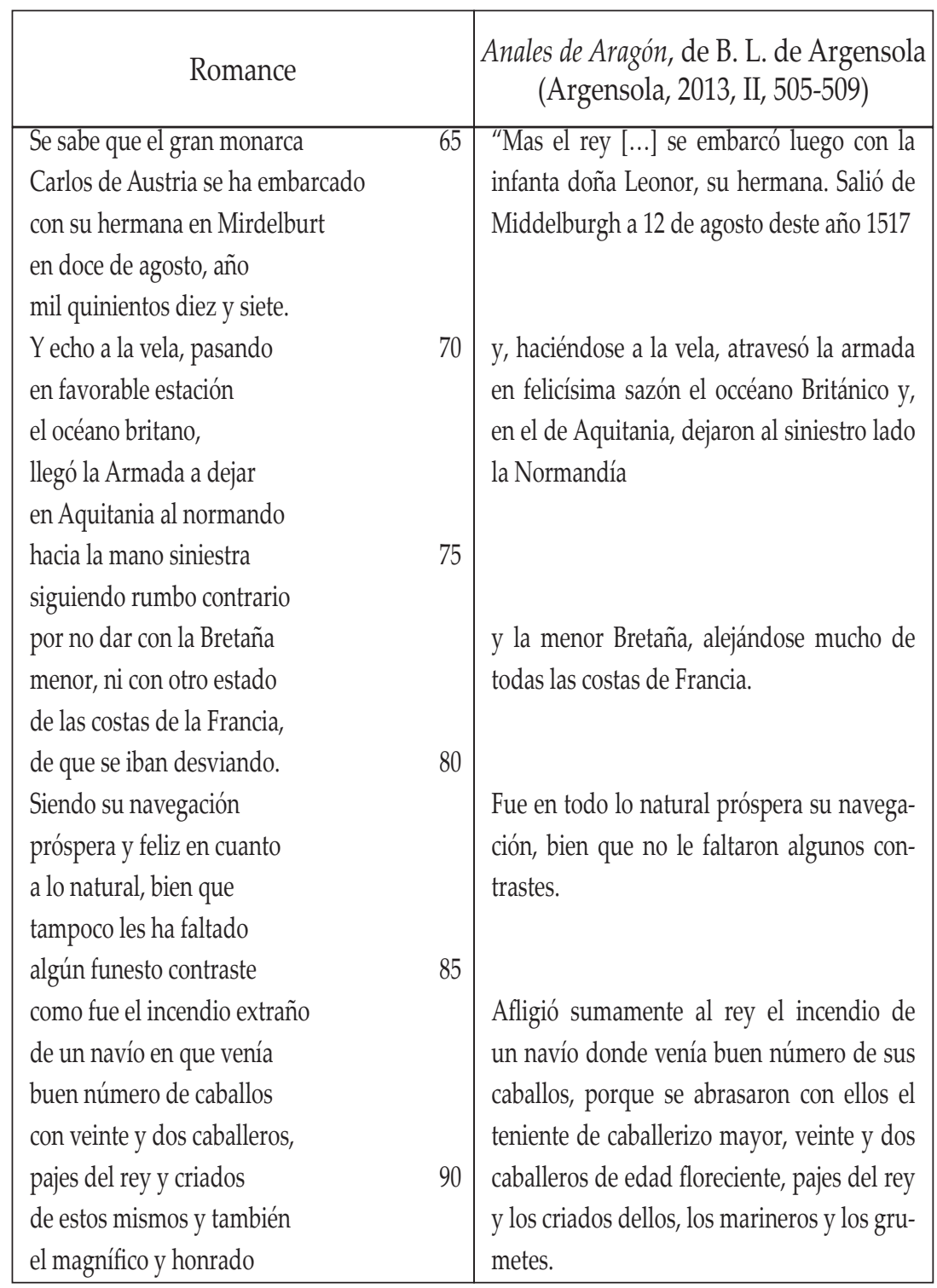




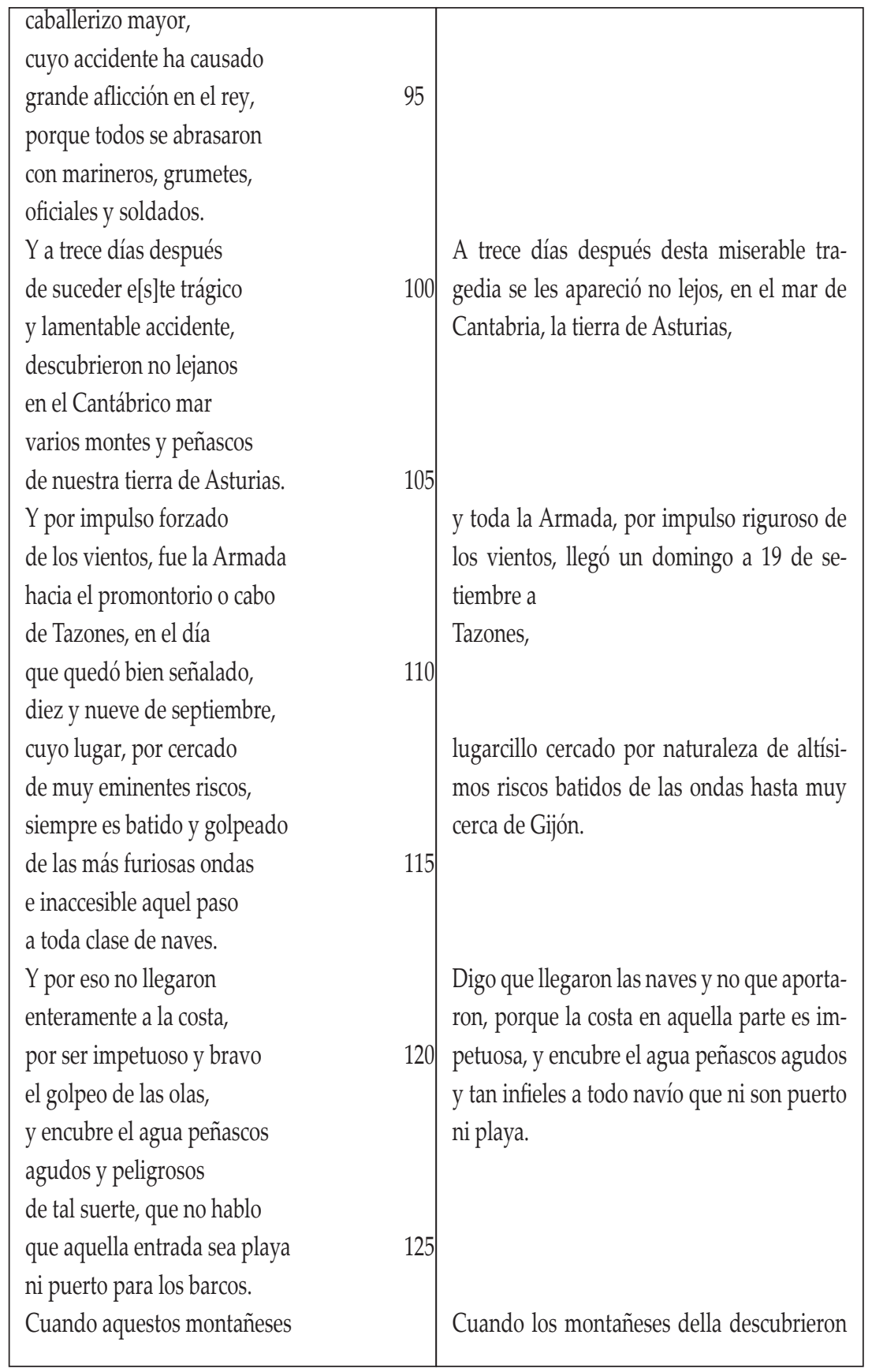




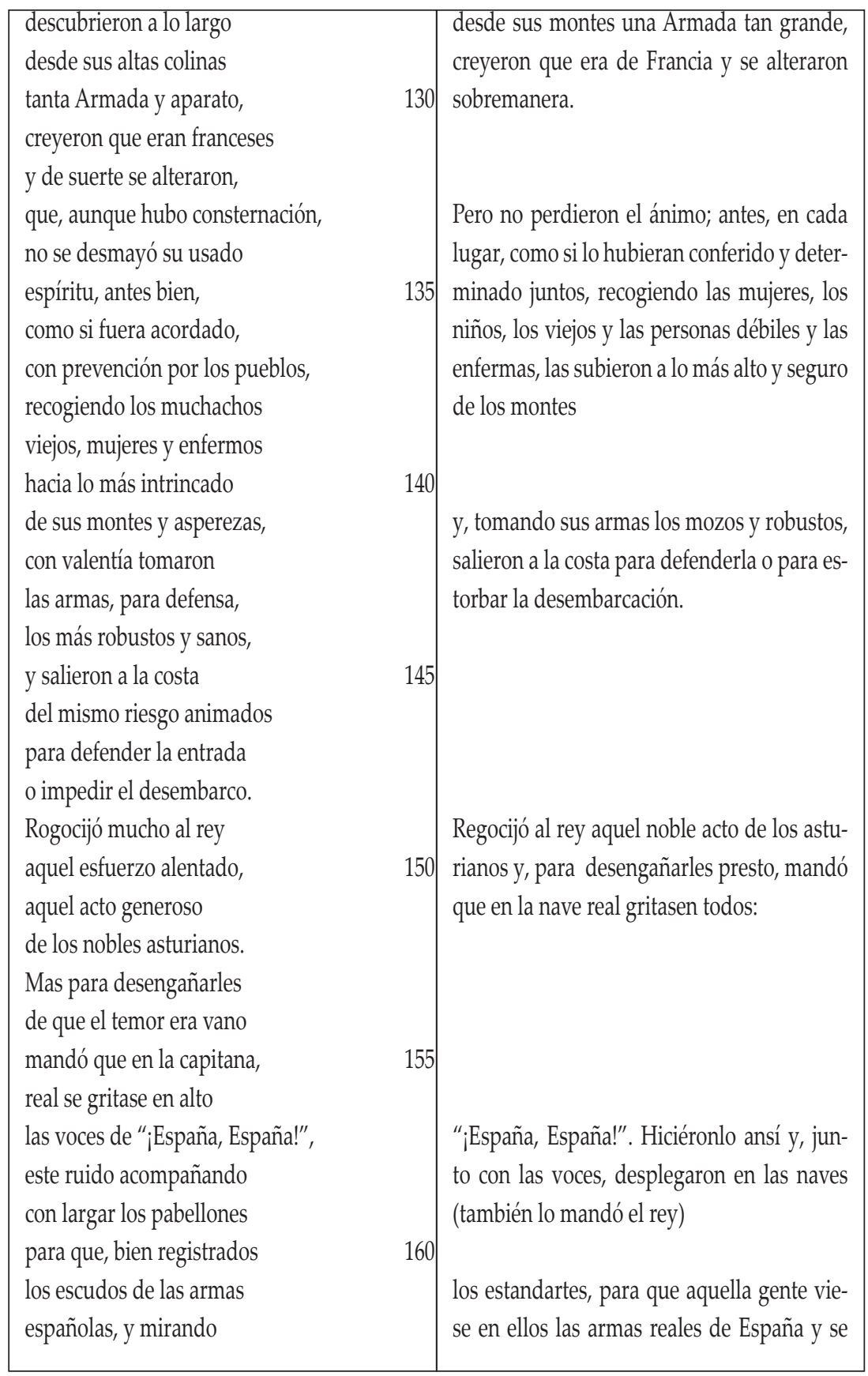




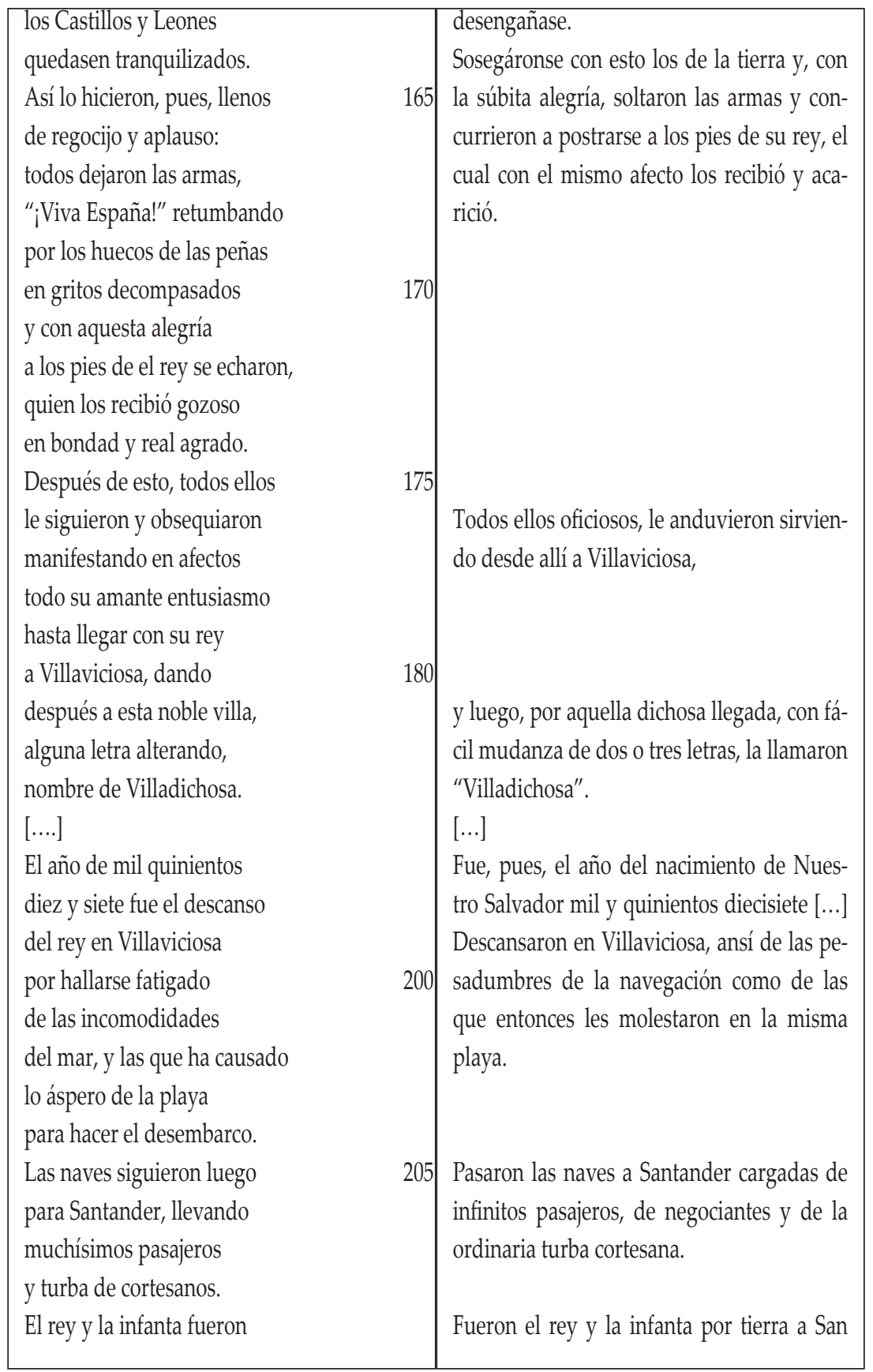




\begin{tabular}{|c|c|c|}
\hline $\begin{array}{l}\text { a San Vicente, asociados } \\
\text { del Camarero Mayor } \\
\text { monsiur de Jeures, Lasao, } \\
\text { Borrebat y Lanoy, por ser } \\
\text { los principales privados } \\
\text { del monarca, y por lo mismo } \\
\text { residían a su lado. } \\
\text { Uno, de Caballerizo } \\
\text { Mayor; el otro, en el grado } \\
\text { de Mayordomo Mayor } \\
\text { del rey. Y monsiur Lasao, } \\
\text { Gobernador de Castilla } \\
\text { que fue por aquellos años. }\end{array}$ & 215 & $\begin{array}{l}\text { Vicente de la Barquera, acompañados del } \\
\text { camarero mayor mosiur de Xevres, } \\
\text { del mayordomo mayor Lorenzo Borrebot, } \\
\text { gobernador de Bruselas, del caballerizo ma- } \\
\text { yor Carlos de Lanoy y mosiur de Laxao, go- } \\
\text { bernador que fue de Castilla". }\end{array}$ \\
\hline
\end{tabular}

Ahora bien, no es la de Argensola, con ser la principal, la única fuente historiográfica que alimenta el poema; comparece al menos otra más, también aludida explícitamente:

\begin{tabular}{|l|l|}
\hline \multicolumn{1}{|c|}{ Romance } & $\begin{array}{l}\text { Prudencio de Sandoval, obispo de Pamplo- } \\
\text { na, Historia de la vida y hechos del Emperador } \\
\text { Carlos V (Sandoval, 1846, I, 334) }\end{array}$ \\
\hline $\begin{array}{l}\text { A este asunto, se ha notado } \\
\text { lo que en su historia nos cuenta } \\
\text { (como por curioso rasgo) } \\
\text { el obispo de Pamplona } \\
\text { de estar ya profetizado } \\
\text { este suceso, pues dice } \\
\text { que el vaticinio está claro } \\
\text { en la cláusula siguiente } \\
\text { del tal adivino: "Charco } \\
\text { vicioso, vendrán a ti } \\
\text { muchas gentes en caballos } \\
\text { de madera por el mar, } \\
\text { al gigante acompañando". }\end{array}$ & 195 \\
\hline
\end{tabular}


No obstante lo expuesto, cabe finalmente anotar que, si no nos equivocamos, el poema también malentiende unas líneas de Argensola, lo que lo lleva a trabucar una serie de afirmaciones de este. Así, en los versos relativos al paso por Valladolid y Zaragoza (vv. 223-225),

Pasaron de San Vicente

a Valladolid, y pararon

en Zaragoza después,

probablemente el autor del romance esté confundiendo los protagonistas de las siguientes palabras de Argensola:

Por tierra hicieron su viaje él [Juan Selvagio] y Antonio Agustín, vicecanceller de la Corona de Aragón, y ambos entraron en Zaragoza a los primeros días de setiembre deste año. Recibiéronles con alegría, que para el vicecanceller fue como triunfar de los émulos y autores de la calumnia que le causó aquella pesada persecución. Detúvose en Zaragoza algunos días para componer las cosas de su casa y, habiéndose partido el gran canceller para llegar temprano al recebimiento del rey en la desembarcación, le siguió Antonio Agustín, pero quedose en Valladolid, adonde llegaron después (Argensola, 2013, II, 509).

pues, como se ve, el relato de Argensola se refiere al itinerario de algunos de los privados del rey, y no al del propio monarca.

\subsection{Fuentes documentales}

Si la primera parte de las explicaciones de Tomás se articulan en torno al relato del "dopto" erudito Miguel, que recurre a la versificación literal de fuentes históricas impresas, en la segunda es el propio Tomás quien toma la palabra en primera persona, demostrando una enorme familiaridad con los Hevia y con su archivo familiar, que será constantemente aducido para validar la estancia del César Carlos en la casa. A este respecto, Tomás 
dice haber mirado "por mí mismo en el Archivo / los papeles antiguados" (vv. 263-264); vio "también las concesiones / de los privilegios varios" (vv. 273-274), si bien explica que en el "año de setenta y siete" no pudo ver la confirmación de estas concesiones por ser "tiempo en que yo fui llamado / para informar sobre puntos / de extensión en los teradgos" (vv. 276-280); añade que en otra ocasión coincidió con "don Diego del Valle haciendo / un gran registro" (vv. 283-284) de los papeles de la casa; y aun mucho antes, "el señor don Diego de Hevia / me había bien informado / de muchos particulares" (vv. 291-293) sobre el archivo $y$, se entiende, la estancia de Carlos I en la casa.

En todo caso, esta continua referencia a la documentación del archivo familiar proporciona, más allá de una cumplida labor por parte del poeta-historiador, un sólido apoyo documental a la tesis defendida. De manera claramente ilustrada, la presencia del monarca se atestigua con numerosa documentación real. Al tiempo que se desarrolla esta clara estrategia discursiva, el poema nos ofrece una fidedigna visión del fondo de la Casa Hevia - “a quién hemos de dar fe / (...) si no / a documentos tan claros" (vv. 379-381-382), "pergaminos y atestados" (v. 384) - Las menciones y empleos de esta colección familiar son recurrentes a través de los siglos modernos, proporcionándonos una imagen acorde con lo que se puede considerar propio de cualquier archivo familiar de la aristocracia rural asturiana. Es frecuente el empleo de la memoria documental del linaje por parte de los señores como prueba judicial en diferentes procesos incoados por ellos, tales como el memorial elevado en 1686 a Carlos II solicitando infructuosamente el privilegio de cadena jurisdiccional para el palacio villaviciosino (Concha García-Mauriño, 2001) o la defensa de las propiedades y jurisdicciones de la casa frente al reformismo borbónico de la Junta de Incorporación en 1707, en el pleito de tanteo de 1760 frente a sus vasallos y en el estudio subsiguiente a la abolición de los señoríos en 1826 para aclarar la propiedad del Coto de Poreño (Solano Fernández-Sordo, 2017b). 
Sin embargo, esta última fecha debió marcar de algún modo el final -incluso materialmente hablando- del archivo de la Casa Hevia. La última referencia que tenemos a este fondo que permite ver la conservación de una nutrida colección documental la transmite José Caveda y Nava al remitir a finales de la década de 1820 a la Real Academia de la Historia su informe sobre el concejo de Villaviciosa para el Diccionario de Martínez Marina, comenzado y elaborado en su mayor parte por su padre (Friera Suárez, 2019, III, 1498-1506). En él, Caveda y Solares anota al comentar los diplomas fundacionales de la casa que "todos estos privilegios se conservan en pergamino en el archivo de esta casa". Tras ello, bien por la francesada o bien por el traslado del solar del linaje que basculaba más hacia Gijón con la vinculación a la Casa de Jove ${ }^{17}$-lo que, en última instancia, explica la conservación del actual fondo villaviciosino en el palacio familiar gijonés hasta hace unos años - , el rastro del archivo de la Casa de Hevia desaparece ${ }^{18}$. Por eso el poema que ahora damos a conocer constituye también un testimonio de la historia archivística del fondo familiar, pues representa de algún modo - aunque sea parcialmente - una descripción de su contenido. Siendo más detallados, cabe proponer un índice la documentación aludida a lo largo del poema para probar el alojamiento del Emperador, como a continuación ensayaremos, refiriéndonos especialmente al problema de su conservación. Así, en el romance se hace referencia:

1. A un "traslado / de cierto real privilegio / sobre el voto de Santiago" existente en el archivo catedralicio ovetense (vv. 42-44), a lo que ya aludimos a la hora de comentar la personalidad y misión de Sebastián de Navia.

17 Ésta se produce de forma definitiva con el matrimonio de Vicenta de Hevia - primera heredera de la cabeza de una familia ya desvinculada de señoríos por las medidas liberales - con Matías de Jove Balbuena en 1823, y el nacimiento de su primogénito Placido Jove Hevia, importante hombre de letras del Romanticismo asturiano (Miguel Vigil, 1892, 78)

18 Así, para una fecha como 1884 se nos transmite la noticia de que en esta casa sólo se encontraba la carta de legitimación de Gutierre de Hevia - hoy perdidapor los reyes Juana y Carlos (Fernández Ladreda, 1884, 82-83). 
2. A un recibo en el que se atestiguaría que "don Rodrigo ha pagado / un buey que se desgració / en la conducción en carros / del tren de su Alteza Real" (vv. 265-269). Esta noticia resulta novedosa en lo que se conocía acerca de la intervención de los Hevia en la acogida a don Carlos, pero de ser cierta no parece en absoluto extravagante o imposible. El propio Vital transmite en su relato de esos días que "los furrieles y alguaciles contrataban carretas y mulos para llevar los bagajes del rey y sus gentes, lo cual se acabó y logró con gran trabajo" (Vital, 1992: 165). Así pues, aunque no se haya conservado mayor constancia de este recibo, bien podría encontrarse entonces en el archivo de la Casa como prueba de esos "algunos servicios que me hicisteis cuando posé en vuestra casa" (Solano Fernández-Sordo, 2017b: doc. 17).

3. A "privilegios varios / de la Casa" (v. 274-275) comprobados y aprobados el "año de 77" (v. 277). El que se haya perdido el archivo impide conocer si ese año tuvo lugar algún tipo de autentificación de los privilegios originales; aunque cabe presumirla como parte del conflictivo proceso que siguió a la muerte ab intestato del señor José Lorenzo de Hevia Bernardo en 1776 (Miguel Vigil, 1892: 78) y sucesión del señorío en su primogénito Antonio Lorenzo, quien no obtuvo plena posesión del mismo hasta $1781^{19}$.

4. A una carta del señor de Chièvres dirigida a Rodrigo de Hevia y aparecida en el archivo familiar (vv. 295-304). Ciertamente, la referencia a esta misiva parece en cambio fantasiosa, quizá una licencia hiperbólica que se permite el poeta para engrandecer a la familia con la idea de una posible relación de amistad de los Hevia con los primados del rey nacida en la breve estancia. Es continuación lógica de la anécdota de que don Gonzalo de

19 Así lo refiere el inventario de vínculos de la Casa conservados en el archivo familiar (Archivo Municipal de Villaviciosa, Fondo Jove Hevia, carp.1.2, exp. 1; y carp. 1.3, exp. 1). 
Hevia siguió viaje con Carlos de Gante hacia la corte también sumamente sospechosa de invención-, pues se supone que en esta carta el flamenco escribiría a Rodrigo sobre el feliz término del viaje "noticiándole el estado / de la salud de los reyes / y de su padre" Gonzalo. Desde luego, no puede afirmarse tajantemente su carácter fabuloso ante la ausencia de archivo, pero su existencia resulta cuando menos poco verosímil.

5. A varios documentos que permiten a Rodrigo de Hevia fundar mayorazgo en su hijo legitimado (vv. 305-316), al que posteriormente se sumarían otras regalías firmadas "en Burgos / con privilegio sellado" (vv. 319-320). Cabe pensar que fuese el documento original de institución del Mayorazgo de la Casa de Hevia, así como el del privilegio de Juana y Carlos que le daba licencia para ello, hoy conservados por copias posteriores. No obstante, no nos consta ninguno de ellos concedido en Burgos, por lo que bien pudiera ser una aprobación regia a los pactos posteriores a la institución del mayorazgo entre padre e hijo en la década de 1540 que no se ha conservado (Bellmunt y Canella, 1907, II, 118, n. 1; Solano Fernández-Sordo, 2017b, docs. 17, 30-33).

6. A la condonación por parte de "don Gonzalo / al puerto de los Tazones / cien libras de los pescados / de doscientas que pagaban / por tributo indispensable" (vv. 336-342). Si bien no sabemos del rastro documental que pudiera haber dejado esta gracia del primer Hevia a los pescadores tazoneros y ni siquiera si esta reducción tuvo lugar, sí se constata que la renta debida por estos a la familia era de dicha cantidad: un cuaderno del cobrador de las rentas de la casa señala en 1816 que "el Gremio de Tazones tienen que pagar cada año a los señores de esta Casa de Hevia por el sitio de la plazuela y cabrestantes cien libras de pescada cicial, y mientras no haiga de esta especie cien libras de pescada fresca, de merluza, congrio, ruviel o rodaballo; 
y en partidas y días diferentes, que no pase cada bez de ocho o diez libras menores" ${ }^{20}$. Gracias a ello conocemos que el origen de esta renta no es señorial o jurisdiccional, sino meramente funcional por el uso del solar bajo la torre familiar en este lugar, una ensenada portuaria sin duda empleada por los pescadores y marineros para sus trabajos - no en vano ahí se emplazan los cabrestantes, aún hoy visibles reconstruidos-.

7. Y al privilegio que hacía que la casa de Hevia sirviera "de asilo y sagrado / a todos los delincuentes" (vv. 322323) por haber residido en ella un rey. Algo que sabemos que se producía de manera natural hasta al menos el siglo xvII, cuando en cambio se intentó marcar materialmente disponiendo una cadena en el palacio que señalase el privilegio; lo cual se pidió infructuosamente mediante un memorial elevado a Carlos $\mathrm{II}^{21}$. Sin embargo, esta costumbre, así existente sin refrendo oficial que conozcamos, se mantuvo hasta que Carlos III "tuvo por bien reformarlos / con capillas y conventos / y otros lugares sagrados, / por no aumentar los delitos / con tan fáciles amparos" (vv. 326-330). Ciertamente, tal como el poema recoge, el monarca, de acuerdo con la reforma borbónica, abanderó la reducción de las jurisdicciones privilegiadas y abolió específicamente en 1773 el llamado privilegio de asilo de los lugares de culto (Gortázar Rotaeche, 1996, 53-54).

20 Archivo Municipal de Villaviciosa, Fondo Jove Hevia, carp.4, exp. 1, fol. 31.

21 Dicho memorial lo expone claramente: «por esta raçón [del alojamiento de Carlos] en diferentes ocasiones que se a ofrecido, habiéndose recojido algunos reos en la dicha casa con temor de la justicia, no los sacavan sin liçençia del poseedor de ella, como consta de la Información que se presenta y traslado de la dicha facultad. En consideración de lo qual y de la honrra que recibió la dicha su casa, suplica a Vuestra Magestad que para que permanezca esta memoria [...] se sirva de haçerle merçed de mandar se ponga en ella cadena y goçe de las demás gracias y prerrogativas que en semejantes ocasiones se an concedido a las casas donde se a alojado Vuestra Magestad y otros señores reyes sus predeçesores» (Archivo Histórico Nacional, Consejos, leg. 4457, exp. 34, fol. 1v). 
Con respecto al estatuto de la casa de los Hevia como "sagrado", esto es, como jurisdicción privilegiada, encontramos otra referencia en las décimas - en realidad, la única alusión erudita de estas, de tono, como se ha dicho, más directo y agresivo que el del romance- - Se lee en ellas, en referencia a la estancia de Enrique de Trastámara en el Hospital de San Miguel, en Las Regueras (Trubia):

El ser la casa sagrado

mayores prueba previene

porque ninguna le tiene

en que el rey no hubiese estado.

Pues hasta un corto hacendado

que hoy en Las Regueras para

aquesta exención preclara

en su pobre casa tuvo

solo porque en ella estuvo

Enrique de Trastamara.

Capítulo importante aparte, no reseñable por su naturaleza junto al anterior acopio documental, aunque sí en cierto modo asimilable debido al valor probatorio del pasado que nuestro poeta-historiador le atribuye, es el hecho de que "se conserva con cuidado / la mesa en que el rey comió / y el cuarto en que ha reposado" (vv. 270-272). Algo que, de no haber tenido lugar el hospedaje carolino, como pregunta también el autor, nunca se hubiera producido - ¿'a qué fin el conservar / por tanto número de años / aquellos antiguos muebles / mudos testigos del caso?" (vv. 373-376)—. Ciertamente, esta conservación del mobiliario como memoria material de la casa es algo que se registra ya tempranamente, pues en el citado memorial de la cadena de 1686 se dice que "se conserva presente en ella una sala que comúnmente llaman del Emperador, la qual está separada con el decoro y decençia que es justo" 22 , y todavía un inventario de bienes de la 
Casa en 1813 recoge entre las estancias el "cuarto de estrado del rey y sus oficinas" ${ }^{23}$. Y ahí registran los citados cuarto y mesa $-\mathrm{y}$ en ocasiones también una cama y un asiento - los diferentes estudiosos que hablan de la casa durante el siglo xix hasta la donación a finales de esa centuria al madrileño Museo del Ejército por los últimos herederos de la parentela (Bellmunt y Canella, 1907, II, 118; Cavanilles, 1863, 143; Mallo Fernández-Ahúja, 2003, 155; Friera Suárez, 2019, III, 1573) ${ }^{24}$.

Por fin, tras el relato histórico y la constante alusión a los documentos que atestiguan los favores recibidos por la familia a causa de haber acogido al emperador, una última razón se esgrime en el romance para defender el papel principal de los Hevia: a secas, la verosimilitud de lo sucedido por la ubicación de su casa fuerte. Según reza el poema, "estando / su torre tan inmediata / y al frente del desembarco, / ¿qué cosa más natural / que buscarla un fatigado / monarca para su alivio" (vv. 356-361). Y, en definitiva, cuál si no esta podía ser la razón que justifique la relevancia adquirida por la casa de Hevia, probada histórica y documentalmente: "no siendo así, ¿qué fin / podían ser despachados / los privilegios que aquí / quedan especificados?" (vv. 369-372).

23 Información procedente de un manuscrito firmado por Manuel José Pérez García que el Archivo Histórico Diocesano de Oviedo conserva dentro del fondo de la parroquia llanerense de San Cucao y titulado Villaviciosa. La Casa de los Hevia (fol. 3). Se trata de un estudio misceláneo realizado en la década de los noventa por este erudito sobre documentación hasta ahora desconocida de la Casa de Hevia que fue a parar a esta parroquia de Llanera.

24 Por su parte, la mesa de los Hevia se halla inventariada y descrita en el Catálogo de los objetos que contiene el real Museo militar a cargo del cuerpo de artillería $(1856,331)$. 


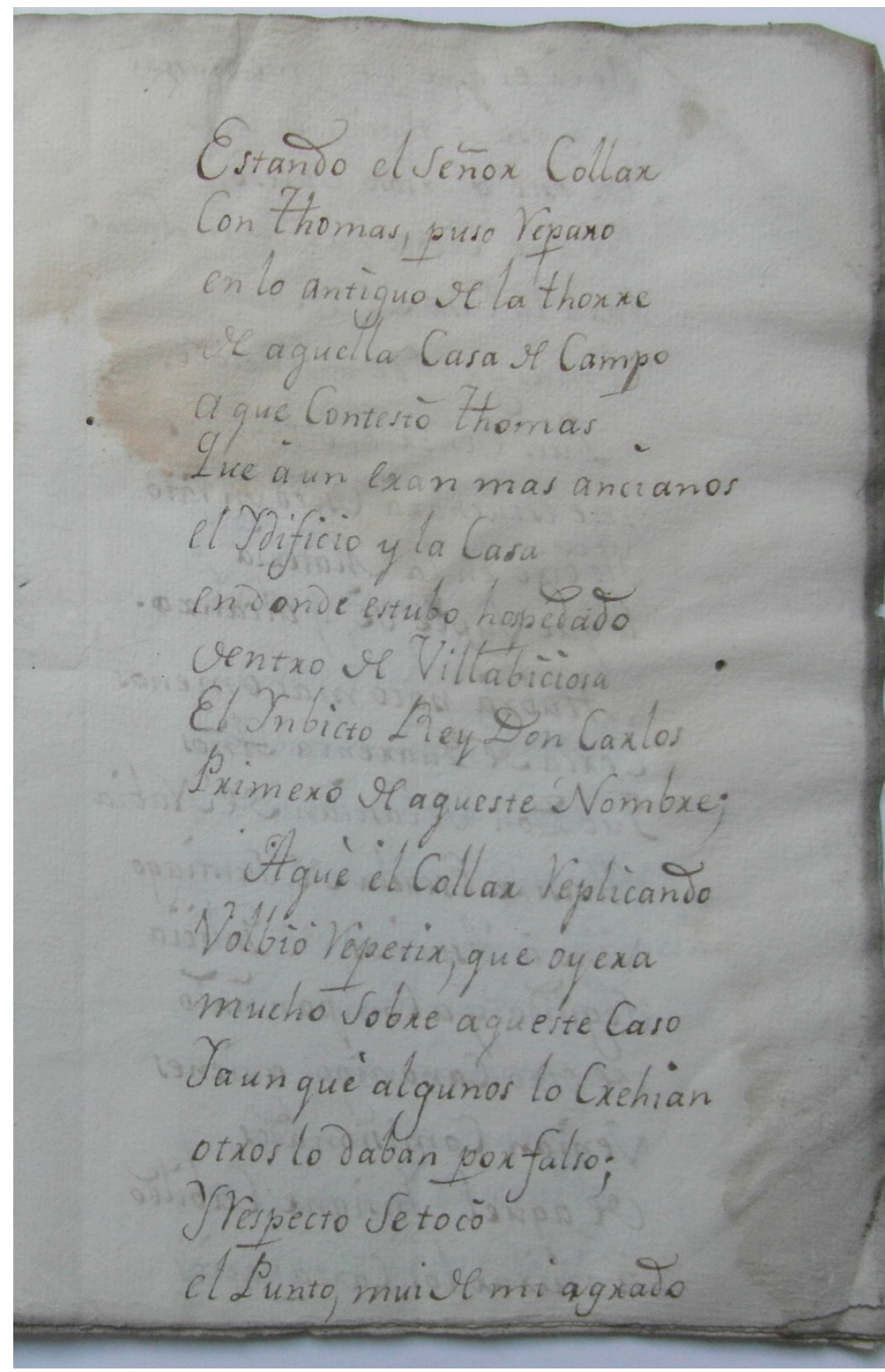

Archivo Municipal de Villaviciosa, Fondo Jove Hevia, doc. 8.1 (fol. 2r). 


\section{Poesía, historia y memoria: reflexiones finales}

Como se ha podido comprobar a lo largo de las páginas precedentes, el conjunto de cuatro poemas constituye un verdadero documento literario a la vez que un ensayo histórico. Es, simultáneamente, la narración de una anécdota y la vindicación de un protagonismo en la historia. Como a ningún lector escapará, la secuencia se presenta como un juicio de parte, una exposición parcial que ostentosamente toma posición en el debate acerca de la veracidad del episodio frente a los escépticos que "solo saben dudar, / y, si se ofrece, negar, / pero sin dar la razón" (vv. 430-432), llegando a cierta violencia verbal en las décimas finales. Pese a que no se conserva mayor testimonio de tal disputa doméstica, no resulta para nada extraña a los comportamientos de la sociedad villaviciosina y asturiana de finales del setecientos. No eran infrecuentes los debates similares sobre los legendarios orígenes familiares de las parentelas principales, que oponían el ansia racional de una ciencia histórica que como tal comenzaba a despegar a los relatos más o menos fabulosos de quienes para prestigiar su blasón hacían - o venían siglos haciendo- de sus antepasados protagonistas de pretéritas hazañas nacionales. Y, no en vano, si podían ver amenazada la autenticidad del desembarco y hospedaje regio de 1517, los partidarios de la Casa de Hevia hacían bien en defenderla, pues de ello dependía su propia existencia. Así se entiende la enardecida y erudita exposición que nuestro poeta-historiador hace por medio de Tomás a un inocente y extranjero señor Collar que sirve de oyente bienintencionado y ha de quedar convencido. $\mathrm{Y}$ es que prácticamente nada se conoce o debía de conocerse de la familia con anterioridad al episodio y a los favores y privilegios que le granjearon. Sirva de prueba, por ejemplo, que si sabemos siquiera el nombre de los padres y antepasados de Rodrigo de Hevia es porque él mismo los refiere en 1529 a la hora de establecer el mayorazgo (Cuesta Fernández y Díaz Caneja, 1958, n. 5). La historia -y de algún modo la nobleza - de la familia Hevia dependía en buena medida de la autenticidad de que tal acontecimiento quedase 
fuera de toda duda, lo que explica poemas proselitistas como los que aquí estudiamos; de la necesidad de preservar su recuerdo ya advertía el propio Carlos I a los pocos meses de su visita, pues concede el mayorazgo "porque de vos y de ello quede perpetua memoria" (Solano Fernández-Sordo, 2017b, doc. 17).

Los Hevia aceptaron el consejo, de modo que se ocuparon de preservar la documentación - y hasta los muebles - que atestiguaban el suceso. Basta la consulta a buena parte de la documentación generada por los señores de la Casa en los siglos siguientes para comprobar que la referencia a los "servicios fechos quando yo el rey bine de nuestro señorío de Flandes a estos nuestros reynos y posé en vuestra casa" es frecuentemente argumento esgrimido para solicitar mercedes y favores regios o defender derechos (Concha García-Mauriño, 2001; Solano Fernández-Sordo, 2017b, doc. 17, 30-33). A la vista de los hechos, la composición de esta obra poética por alguien sin duda cercano a la familia es una iniciativa más en esta dirección; aunque en este caso no destinada a la defensa en tribunales jurídicos sino ante el juicio del pueblo y su opinión. No creemos muy descabellado pensar que se trate de una composición pensada para llegar a las calles de Villaviciosa - especialmente la parte del romance, que lleva la mayor parte de la carga probatoria -, donde quizá entre los vecinos había calado el mensaje de duda de familias rivales.

Pero, a diferencia de otros linajes cuyos orígenes decían surgir en la participación de sus antepasados en una importante batalla medieval - puede escogerse cualquiera entre la Covadonga pelagiana o la toma de Granada-, en la meritoria salvación de un rey o una dama destinada al ominoso tributo de las cien doncellas o en la descendencia directa de personajes ilustres como los mismísimos Reyes Magos (Calleja Puerta, 2004), los Hevia sí podían probar su relato germinal. Así lo hace el poeta-historiador en estos textos, evidenciando una gran pericia investigadora.

Desde luego, pese a que podemos tratar de ver en los mencionados personajes el rastro de personas reales, resulta imposible determinar si verdaderamente se produjo la conversación que se 
narra entre el señor Collar y Tomás en el Torrexón de Tazones y aun la visita de Sebastián de Navia y sus acompañantes a la casa, pues todo podrían ser recursos literarios del poeta. Ahora bien, es en cambio indudable el valor historiográfico del texto para rastrear las fuentes archivísticas y la literatura histórica que avalan su argumentación. Ciertamente, no podemos señalar que presente grandes novedades informativas para reconstruir los hechos de 1517, dado que en una primera parte se apoya y versifica casi plagiariamente fuentes conocidas entonces y ahora sobre el desembarco, como las de Argensola o Sandoval - quienes, por otro lado, en nada se distancian de otras narraciones más cercanas a los hechos como las de Vital o Mártir de Angleria - y en su repaso diplomático habla de documentación conocida y de algún modo conservada hasta hoy. Entre las noticias novedosas apenas pueden señalarse el posible pago de uno de los bueyes de la caravana carolina por parte de don Rodrigo o la rebaja de la renta por el usufructo de la ensenada de la torre a los tazoneros; así como los menos probables beneficios eclesiásticos del chantre, carta de Chievres o experiencia cortesana de Gonzalo de Hevia en su senectud.

Son, en todo caso, datos singulares que aportan siquiera más luz acerca de un episodio que conocemos hoy relativamente bien. Pero, sobre todo, son testimonio ilustrado de la labor de fino historiador y sistemático trabajo de búsqueda y contraste documental; así como prueba palpable de la conciencia archivística de las familias y el valor probatorio y fedatario de los archivos para una disciplina histórica que comenzaba su "revolución cientifista" incluso para los asuntos domésticos de una pequeña villa asturiana. Todo ello confluía en nuestro poeta-historiador que, de todas maneras, no renunciaba a la belleza formal de su obra y plasmó sin problema su investigación en versos ilustrados para memorias medievales.

\section{Criterios de edición}

La edición del presente texto no ofrece especiales dificultades. Nos hallamos ante un caso de codex unicus, en que no cabe sino 
seguir la fuente conocida. Al hacerlo, modernizamos ortografía y puntuación, pero mantenemos aquellos aspectos con valor fonológico en el momento ("dopto", "rogocijó", "teradgo", "retor"). En todo caso, hemos de tener presente que nos encontramos ante una copia en limpio y no un original, lo que atestigua su letra uniforme y clara y los errores que presenta. Para empezar, los defectos de rima nos permiten postular la falta de cuatro versos en los tres siguientes pasajes. Como se echa de ver, en un romance deben rimar los versos pares, lo que nos permite deducir que si aparecen dos versos rimados seguidos, se ha de haber perdido uno sin rima entre ellos (caso 1); y si constan dos versos seguidos sin rima, debe faltar en medio uno rimado (casos 2 y 3 ):

1)

cuyo autor sigue a Zurita

y es Bartolomé Leonardo

$[\ldots \ldots \ldots \ldots \ldots \ldots \ldots \ldots \ldots . .$.

de Argensolo, prebendado

en Zaragoza y retor

de Villahermosa, nombrado

2)

tres piezas de que ha gozado:

que lo fueron la Chantría

[............................]

de Oviedo, y dos beneficios

muy pingües y titulados,

260

3)

"al puerto de los Tazones

cien libras de los pescados

de doscientas que pagaban

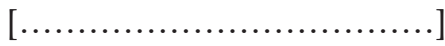

"antes a los sucesores

$[\ldots \ldots \ldots \ldots \ldots \ldots \ldots \ldots \ldots \ldots . .$. 
por tributo indispensable

en una vez cada año;

Es cierto que en el caso 1 parece difícil suponer qué texto se habrá perdido ("Leonardo... / de Argensolo"), lo que acaso pueda poner en duda nuestra consideración del pasaje como trunco - en todo caso, el defecto de rima es incuestionable-; pero incluso en este pasaje nos cabe proponer una conjetura que hace verosímil la laguna:

y es Bartolomé Leonardo

t(el hermano de Lupercio) + [verso supuesto]

de Argensolo, prebendado

Dejando al margen estos cuatro versos omitidos, la secuencia también presenta un verso hipométrico, "entonces por cronista" (v. 237), heptasílabo en lugar de octosílabo; aunque conjeturar una alternativa no es difícil, pues es muy probable que el original leyera "entonces para cronista"; probablemente, el para estuviese abreviado en el texto que nuestro testimonio siguió y el copista no fue capaz de interpretarlo adecuadamente ${ }^{25}$.

También llama la atención que se mencione a "Argensolo" (v. 234) - la lectura del manuscrito es inequívoca- cuando en otro lugar de la secuencia la referencia a "Argensola" (v. 451) es incuestionable, hasta el punto de que debe rimar con bataola; $\sin$ embargo, hablar de error en este caso es más dudoso, pues la leve deformación del apellido puede tener alguna intención expresiva, de modo que no la corregiremos por divinatio.

25 Como nos advierte oportunamente uno de los revisores anónimos de este trabajo, otra conjetura que resolvería la hipometría de este verso sería "entonces por coronista", epéntesis esta última efectivamente muy frecuente, como puede comprobarse en el CORDE, en que se recogen numerosísimos ejemplos de la literatura medieval y de los Siglos de Oro. Entre las más escasas pero no insólitas ocurrencias dieciochescas, puede citarse su utilización por parte de Arzans de Orsúa y Vera en su Historia de la villa imperial de Potosí $(1945,178)$. 


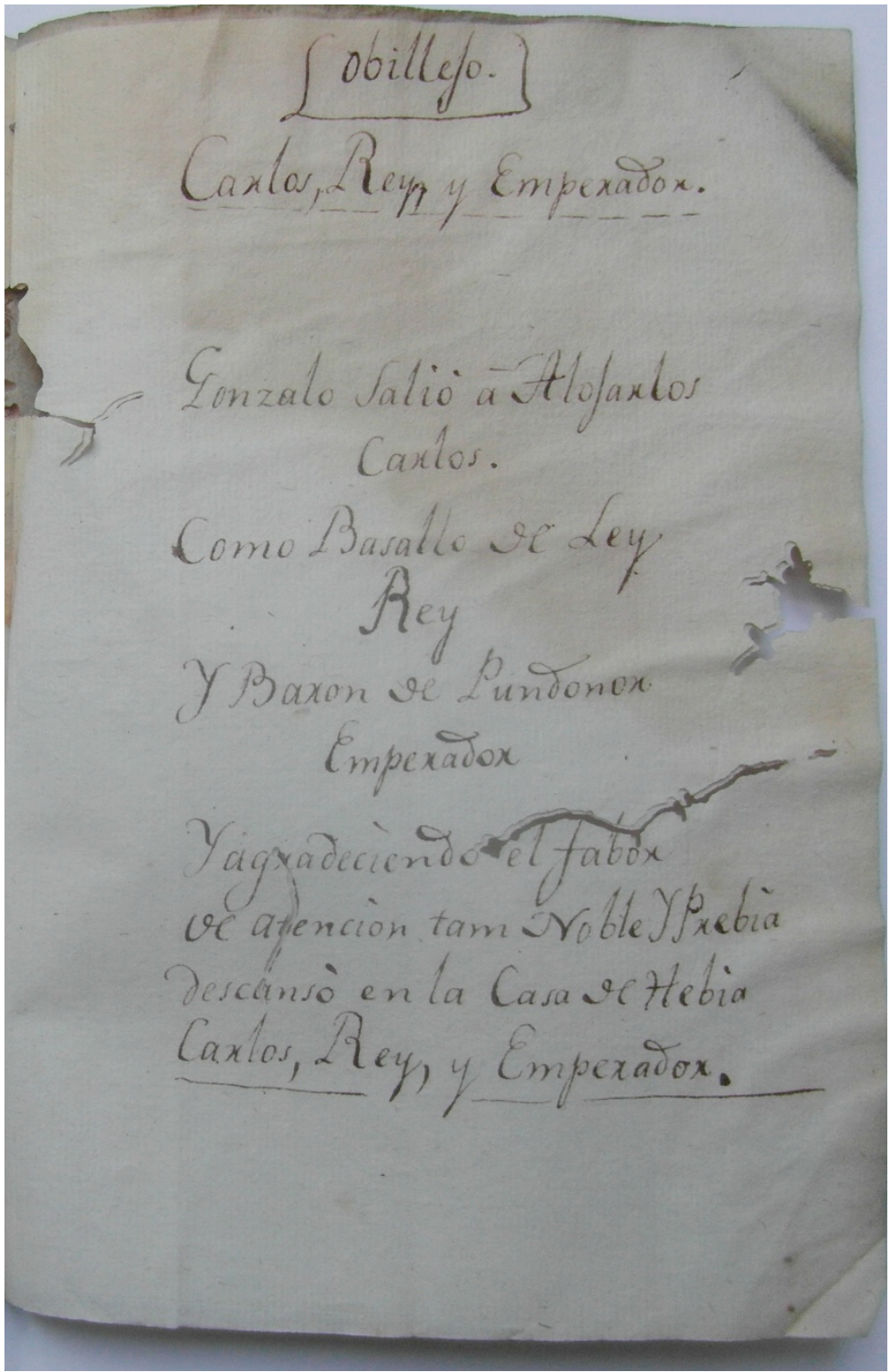

Archivo Municipal de Villaviciosa, Fondo Jove Hevia, doc. 8.1 (fol. 15r). Ovillejo final 
Finalmente, en referencia ahora a una peculiaridad métrica del texto, nos cabe anotar que en las décimas constan dos casos de desplazamiento acentual, lo que no es inhabitual; en ellas, procer (v. 466) ha de realizarse como aguda, pues rima con tener; y Trastamara (v. 482) como llana, pues rima con preclara.

En conclusión, ofrecemos a continuación el texto con las pertinentes adaptaciones ortotipográficas: para mayor claridad, ofrecemos entre comillas el largo parlamento de Tomás (vv. 25416); y en cursiva el momento en que dentro del relato de este se reproduce en estilo directo el del "dopto" erudito (vv. 65-261). Por lo demás, no anotaremos el poema, pues sus muy abundantes referencias eruditas, históricas y contextuales ya han sido aclaradas y comentadas en las páginas precedentes. 


\section{Edición de los poemas}

Poemas sobre el desembarco y estancia de Carlos de Gante en la casa-palacio de los Hevia en Villaviciosa

(AMV, Fondo Jove Hevia, doc. 8.1)
ILUSTRE Y ESTIMABLE MONUMENTO
EN QUE EL MONARCA MÁS ESCLARECIDO,
DESCANSANDO DURMIÓ, Y TOMÓ ALIMENTO
DE LAS CERÚLEAS ONDAS PERSEGUIDO;
PARA SIEMPRE SERÁS MUDO ARGUMENTO
DEL TIEMPO Y DE LA EDAD ENVEJECIDO,
QUE DÉ A LA CASA DE HEVIA HONOR GLORIOSO
Y MORTAL PESADUMBRE AL ENVIDIOSO.

\footnotetext{
Estando el señor Collar

con Tomás, puso reparo

en lo antiguo de la torre

de aquella casa de campo,

a que contestó Tomás

que aún eran más ancianos

el edificio y la casa

en donde estuvo hospedado

dentro de Villaviciosa

el invicto rey don Carlos

primero de aqueste nombre.

A que el Collar, replicando,

volvió repetir que oyera

mucho sobre aqueste caso,

y aunque algunos lo creían,

otros lo daban por falso.

$\mathrm{Y}$ respecto se tocó

el punto, "muy de mi agrado

será el que usted me ilustre,
}

si acaso ha entendido algo

20

de este glorioso suceso,

porque cierto ha sido un lauro

para la Casa de Hevia,

5 el más grande señalado".

"Pues, señor", dijo Tomás,

25

"me escuchará usted un rato

y le diré en la materia

lo que supe, sé y alcanzo.

10 "Habrá poco más o menos

cerca de cuarenta años

30

que don Sebastián de Navia,

maestre escuela de Santiago,

"vino a Asturias, de Galicia

15 seguido y acompañado

de otro canónigo, quienes

35 "de aquel insigne Cabildo

a mirar los cartapacios 
y becerros de la iglesia

Catedral, por si el cuidado

"de tan hábiles agentes

podía hallar un traslado

de cierto real privilegio

sobre el Voto de Santiago.

"Para cuyo fin traían

consigo un gran literato

y dopto en antigüedades

y caracteres ancianos.

"Estos tres señores, pues,

estuvieron hospedados

en la antigua Casa de Hevia,

donde fueron regalados

"con garbo y magnificencia.

Y como eran inclinados

a leer cosas curiosas,

el archivo registraron

"de la casa, y enseguida,

una tarde comenzando

de propósito a tratar

de la estancia del rey Carlos,

"en ella, escuché de boca

de aquel erudito y sabio

traductor de caracteres

estos históricos rasgos:

Se sabe que el gran monarca

Carlos de Austria se ha embarcado

con su hermana en Mirdelburt

en doce de agosto, año

mil quinientos diez y siete.

Y echo a la vela, pasando

en favorable estación

el océano britano,

llegó la Armada a dejar en Aquitania al normando

40 hacia la mano siniestra

75

siguiendo rumbo contrario

por no dar con la Bretaña

menor, ni con otro estado

de las costas de la Francia,

45 de que se iban desviando.

80

Siendo su navegación

próspera y feliz en cuanto

a lo natural, bien que

tampoco les ha faltado

50 algún funesto contraste

85

como fue el incendio extraño

de un navio en que venía

buen número de caballos

con veinte y dos caballeros,

55 pajes del rey y criados

90

de estos mismos y también

el magnifico y honrado

caballerizo mayor,

cuyo accidente ha causado

60 grande aflicción en el rey,

95

porque todos se abrasaron

con marineros, grumetes,

oficiales y soldados.

$Y$ a trece días después

65 de suceder e[s]te trágico

y lamentable accidente,

descubrieron no lejanos

en el Cantábrico mar

varios montes y peñascos

70 de nuestra tierra de Asturias

de los vientos, fue la Armada

hacia el promontorio o cabo 
de Tazones, en el día

que quedó bien señalado,

diez y nueve de septiembre,

cuyo lugar, por cercado

de muy eminentes riscos,

siempre es batido y golpeado

de las más furiosas ondas

e inaccesible aquel paso

a toda clase de naves.

Y por eso no llegaron

enteramente a la costa,

por ser impetuoso y bravo

el golpeo de las olas,

y encubre el agua peñascos

agudos y peligrosos

de tal suerte, que no hablo

que aquella entrada sea playa

ni puerto para los barcos.

Cuando aquestos montañeses

descubrieron a lo largo

desde sus altas colinas

tanta Armada y aparato,

creyeron que eran franceses

$y$ de suerte se alteraron,

que, aunque hubo consternación,

no se desmayó su usado

espiritu, antes bien,

como si fuera acordado,

con prevención por los pueblos,

recogiendo los muchachos

viejos, mujeres y enfermos

hacia lo más intrincado

de sus montes y asperezas,

con valentía tomaron

las armas, para defensa, los más robustos y sanos,

110 y salieron a la costa

145

del mismo riesgo animados

para defender la entrada

o impedir el desembarco.

Rogocijó mucho al rey

115 aquel esfuerzo alentado,

aquel acto generoso

de los nobles asturianos.

Mas para desengañarles

de que el temor era vano

120 mandó que en la capitana,

real se gritase en alto

las voces de "España, España!",

este ruido acompañando

con largar los pabellones

125 para que, bien registrados

160

los escudos de las armas

españolas, y mirando

los Castillos y Leones

quedasen tranquilizados.

130 Asílo hicieron, pues, llenos

165

de regocijo y aplauso:

todos dejaron las armas,

"¡Viva España!" retumbando

por los huecos de las peñas

135 en gritos descompasados

y con aquesta alegría

a los pies del rey se echaron,

quien los recibió gozoso

en bondad y real agrado.

140 Después de esto, todos ellos

le siguieron y obsequiaron manifestando en afectos

todo su amante entusiasmo 


\author{
hasta llegar con su rey \\ a Villaviciosa, dando \\ después a esta noble villa, \\ alguna letra alterando, \\ nombre de Villadichosa. \\ A este asunto, se ha notado \\ lo que en su historia nos cuenta \\ (como por curioso rasgo) \\ el obispo de Pamplona \\ de estar ya profetizado \\ este suceso, pues dice \\ que el vaticinio está claro \\ en la cláusula siguiente \\ del tal adivino: "Charco \\ vicioso, vendrán a ti \\ muchas gentes en caballos \\ de madera por el mar, \\ al gigante acompañando". \\ El año de mil quinientos \\ diez y siete fue el descanso \\ del rey en Villaviciosa \\ por hallarse fatigado \\ de las incomodidades \\ del mar, y las que ha causado \\ lo áspero de la playa \\ para hacer el desembarco. \\ Las naves siguieron luego \\ para Santander, llevando \\ muchísimos pasajeros \\ y turba de cortesanos. \\ El rey y la infanta fueron \\ a San Vicente, asociados \\ del Camarero Mayor \\ monsiur de Jevres, Lasao, \\ Borrebat y Lanoy, por ser
}

los principales privados

180 del monarca, y por lo mismo

residian a su lado.

Uno, de Caballerizo

Mayor; el otro, en el grado

de Mayordomo Mayor

185 del rey. Y monsiur Lasao,

Gobernador de Castilla

que fue por aquellos años.

Pasaron de San Vicente

a Valladolid, y pararon

190 en Zaragoza después,

225

según lo dicen bien claro

los Anales de Aragón,

que yo mismo he registrado

y creo que está a los folios

195 cuatrocientos veinte $y$ cuatro,

230

cuyo autor sigue a Zurita

y es Bartolomé Leonardo
[..................................]
de Argensolo, prebendado

200 en Zaragoza y retor

de Villahermosa, nombrado

entonces para cronista

del rey y de sus estados

en el Reino de Aragón.

205 Y es constante que, hospedados

fueron en Villaviciosa

el rey, y los que a su lado

iban, en la casa de Hevia,

siendo sucesor Gonzalo

210 de Hevia, a quien llevó el rey

de sus talentos prendado

y le mantuvo consigo

muy querido y estimado 
hasta que falleció en Burgos, cuya muerte han lamentado, con pena, el rey y su hermana por lo que le amaban ambos.

$Y$, en señal de aqueste aprecio, se sabe también que han dado a su hijo don Rodrigo tres piezas de que ha gozado: que lo fueron la Chantría<smiles>ICC1CC1I</smiles>

de Oviedo, y dos beneficios muy pingües y titulados,

Santa Dorodia y Graciolo. "Además de esto, he mirado por mí mismo en el Archivo los papeles antiguados

"de la casa, y leí en uno que don Rodrigo ha pagado un buey que se desgració en la conducción en carros "del tren de su Alteza Real. Se conserva con cuidado. la mesa en que el rey comió y el cuarto en que ha reposado

"Vi también las concesiones de los privilegios varios de la Casa, porque fueron confirmados y aprobados "año de setenta y siete, tiempo en que yo fui llamado para informar sobre puntos de extensión en los teradgos "y más bienes de la Casa. Y llegué a ocasión que, estando don Diego del Valle haciendo un gran registro y estado

250 "de los más de los papeles,

los pude ver a mi salvo,

instruyéndome de todos

cuando los iba ordenando

"el predicho don Miguel.

255 Bien que, antes de este acaso,

ya el señor don Diego de Hevia

me había bien informado

"de muchos particulares.

Y el uno, el haberse hallado

260 en el archivo una carta

escrita del nominado

"monsiur de Jevres, al mismo

don Rodrigo; a quien Urbano

da tratamiento de amigo,

265 noticiándole el estado

"de la salud de los reyes

y de su padre, avisando

de haber sido muy feliz

su viaje. $Y$ de otros varios

270 "documentos también consta

la facultad que le ha dado

con distintas preeminencias

para fundar Mayorazgo,

"que hasta entonces no hubo alguno

275 y de consiguiente es claro

de que aqueste fue el primero,

$Y$, en efecto, le ha fundado

"en su hijo don Gutierre,

que antes había engendrado

280 en la noble doña Elvira

de la Paraja, agregando

"a estas grandes regalías

otras muchas y aprobando 


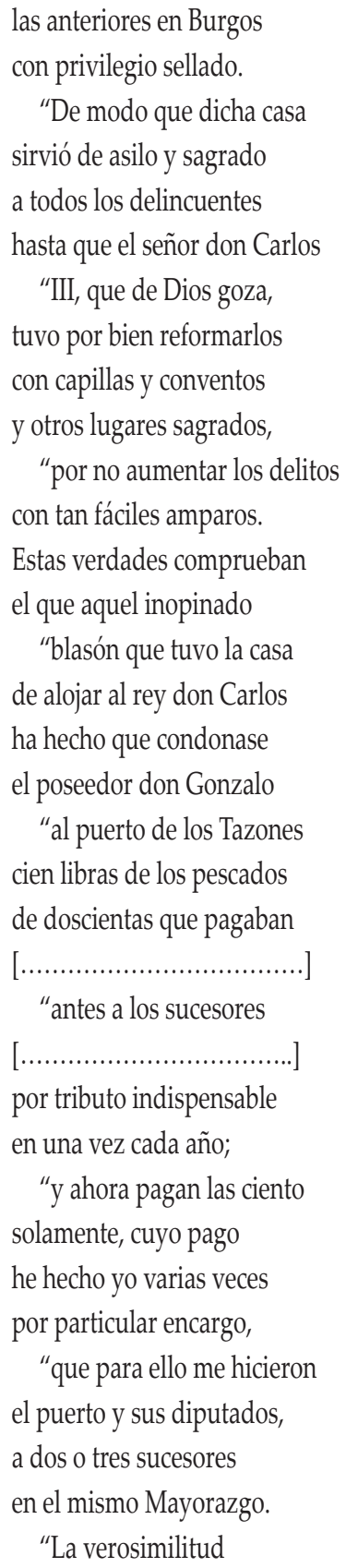

también es constante y claro

320 del que milita a favor

de la Casa, pues estando

"su torre tan inmediata

y al frente del desembarco,

¿qué cosa más natural

325 que buscarla un fatigado

"monarca para su alivio;

y que un honrado vasallo,

como lo era sin duda

dicho señor don Gonzalo,

330 "se la ofreciese a su rey

en tan crítico embarazo

con su persona y hacienda,

familiares y vasallos?

"Y, no siendo así, ¿qué fin

335 podían ser despachados

los privilegios que aquí

quedan especificados?

"¿A qué fin el conservar

por tanto número de años

340 aquellos antiguos muebles

mudos testigos del caso?

"Los argumentos son fuertes, con que así no hay que dudarlo.

¿A quién hemos de dar fe

345 de aquello que no ha pasado

"en nuestra era, si no a documentos tan claros? Si la tradición constante, pergaminos y atestados

350 "de los reyes y ministros más solemnes las historias y cuanto se ha conservado 


"para perpetua memoria
de los sucesos pasados.
Si probase que no estuvo
en Villaviciosa Carlos
"y no arribó a Tazones,
pudiera alguno en tal caso
poner en duda este honor
de la casa de mi amo.
"Y al fin que sus privilegios
podían haberse logrado
por hazañas anteriores
de sus ilustres pasados.
"Pero si la historia da
lo uno por cierto y claro,
y lo otro se acredita
con documentos exactos
"sólo lo podrán dudar
escépticos, arbolarios,
pirrones extravagantes
y algún necio temerario
"a quien más cieguen las luces
que los tenebrosos lagos
del Averno, y que no mira
que este venturoso acaso
"aunque distinguidamente
cede en honor de un paisano,
es también glorioso lustre
de provincia y Principado".

\section{Décimas}

Mas, señor, la emulación no deja a nadie vivir, pues todos quieren subir hasta el cielo su blasón.

390 Nunca guarda proporción

la locura y vanidad

sólo tienen por verdad

lo que juzga su manía,

adopta su fantasía

395 y guarda a su necedad.

Negar una narrativa, aun la más autorizada, para los necios es nada

400 porque no hay quien lo prohíba; mas probar la negativa excede a la operación de su perversa intención, y solo saben dudar,

405 y si se ofrece, negar, pero sin dar la razón.

Los soberbios y orgullosos presumen que desmerecen

410 cuando otros resplandecen con títulos más gloriosos.

Por eso le son odiosos todos los sobresalientes en méritos eminentes

415 y solo encuentran contento 440 en ajar su lucimiento por mil modos diferentes.

No creo ninguno de estos que pretendan disputar esta gloria singular;

415 dirán no estar manifiestos 
los hechos en los autores

más clásicos y mejores.

Pero todo es bataola,

pues nadie iguala a Argensola

entre nuestros escritores.

Fue con tal ingenuidad

continuador de Zurita

que en cuanto escribe, acredita

grande amor a la verdad.

Aquesta sinceridad,

libre de todo cohecho,

de tal suerte prueba el lecho

que queda con su relato

(no siendo algún mentecato)

todo el mundo satisfecho.

¿Qué interés podían tener

mis amos en conservar

mesa, cuarto y más ajuar

del soberano procer?

Claro está que debió ser

porque de todo ello vio;

y prenda en que reposó

tan excelsa majestad

(como pide la lealtad)

hasta ahora se guardó.

El ser la casa sagrado

mayores prueba previene

porque ninguna le tiene

en que el rey no hubiese estado.

Pues hasta un corto hacendado que hoy en Las Regueras para

aquesta exención preclara

450 en su pobre casa tuvo

480

solo porque en ella estuvo

Enrique de Trastamara.

Y, así, es claro, señor, dura,

que solo el genio bilioso

455 del émulo y envidioso

obscurecerlo procura.

Pero una luz tan pura

no podrá su mal humor

apagar el resplandor,

460 porque tiene por rival

490

la tradición más legal

y el más verídico autor.

485

465 Ovillejo

CARLOS, REY Y EMPERADOR

Gonzalo salió a alojarlos

-Carlos-

470 como vasallo de ley

-Rey-

495

y barón de pundonor

-Emperador-.

$Y$, agradeciendo el favor

475 de atención tan noble y previa,

descansó en la Casa de Hevia

500

Carlos, Rey y Emperador. 
ApARATO CRÍtico

V. 237 entonces para cronista I entonces por coronista [conjeturas]] entonces por cronista [lectura hipométrica en el ms.]

\section{Bibliografía}

Argensola, B. L. (1630) Anales de Aragón, Zaragoza, Juan de Lanaja.

Argensola, B. L. (2013) Anales de Aragón, ed. de J. Ordovás Esteban, Zaragoza, Institución "Fernando el Católico".

Arzans de Orsúa y Vera, B. (1945) Historia de la villa imperial de Potosí, ed. de G. A. Otero, Buenos Aires, Emecé.

Avello Álvarez, J. L. (1991) Las torres señoriales de la Baja Edad Media asturiana, León, Universidad de León.

Bellmunt y Traver, O. y Canella Secades, F. (1907) Asturias, Gijón, Talleres de Fototipia y Tipografía de Octavio Bellmunt.

Blecua, J. M. (1974) "Introducción”, en B. L. Argensola, Rimas, t. I, ed. de J. M. Blecua, Madrid, Espasa-Calpe, viI-XLviı.

Busto, X. C. (1997) (ed.) Xosefa Xovellanos, Poesíes, Uviéu, Alvízoras.

Busto, X. C. (2011-2012) “Dos autores de la primer metada del xvır: Xuan Fernández Porléi y Nicolás Torano de la Puerta”, Revista de Filoloxía Asturiana, 11-12, 9-48.

Busto, X. C. (2012) (ed.), B. de L'Auxa / A. Balvidares, Poesíes, Uviéu, Trabe.

Caso González, J. M. (ed.) (1984), G. M. de Jovellanos, Obras completas, t. I, Obras literarias, Oviedo, Instituto Feijoo de Estudios del Siglo XVIII-Ayto de Gijón.

Calleja Puerta, M. (2004) "Historia y falsificación en las pruebas de hidalguía de un caballero andaluz: un estudio histórico-diplomático", en Sulcum sevit. Estudios en homenaje a Eloy Benito Ruano, Oviedo, Universidad de Oviedo, 397-416.

Catálogo de los objetos que contiene el real Museo militar a cargo del cuerpo de artillería (1856), Madrid, Imprenta de Tejado.

Cavanilles, A. (1863) Historia de España, t. V, Madrid, Imp. J. Martin Alegriá. 
Caveda y Solares, F. de P. (1988) Descripción geográfica e histórica del concejo de Villaviciosa, ed. de E. Martínez, Gijón, Auseva.

Concha García-Mauriño, C. (2001) “El Mayorazgo de la casa de Hevia", Boletín de la Academia Asturiana de Heráldica y Genealogía, 7, 65-77.

Cuesta Fernández, J. y Díaz Caneja, M. (1958) “Carlos I en Villaviciosa. El chantre D. Rodrigo de Hevia", Boletín del Real Instituto de Estudios Asturianos, 34, 208-219.

Díaz Alvarez, J. (2012) “El proceso de oligarquización del ayuntamiento de Oviedo bajo los Austrias", Estudis: revista de historia moderna, 38, 139-166.

Domínguez Caparrós, J. (2016) Diccionario de métrica española, Madrid, Alianza.

FAya DíAz, M.a Á. (2003) “Gobierno municipal y venta de oficios en la Asturias de los siglos xvi y xviı", Hispania, 213, 75-136.

Faya Díaz, M. a Á. y Anes Fernández, L. (2007) Nobleza y poder en la Asturias del Antiguo Régimen, Oviedo, KRK.

Fernández Ladreda, M. (1884) El Carbayón: páginas asturianas, Oviedo, Vallina.

Friera Suárez, F, (ed.) (2019) Francisco Martínez Marina. Papeles para el Diccionario geográfico-histórico de Asturias, Oviedo, KRK.

García Carraffa, A. y García Carraffa, A. (1932) Diccionario heráldico y genealógico de apellidos españoles y americanos, t. 43, Salamanca, Imp. Comercial Salmantina.

Givliani, A. P. (1997) “Datos y reflexiones sobre la Junta de Incorporación (1706-1717)", Anuario de Historia del Derecho español, 67, 1029-1038.

Gortázar Rotaeche, C. J. (1996) Derecho de asilo y "no rechazo" del refugiado, Madrid, Dykinson.

JuARisti, J. (2000) El bosque originario. Genealogías míticas de los pueblos de Europa, Madrid, Taurus.

Llano Roza de Ampudia, A. de (1928) Bellezas de Asturias de Oriente a Occidente, Oviedo, Imprenta Gutemberg. 
Madariaga, S. (1979) Cosas y gentes: El libro de los prohombres, Madrid, Espasa-Calpe.

Mallo Fernández-Ahúja, J. (2003) “La casa de Hevia (Villaviciosa): apuntes sobre la arquitectura regional asturiana", Boletín del Real Instituto de Estudios Asturianos, 162, 141-164.

Massin, A. (2012) serie Villaviciosa. Quién vivía en el concejo (55 vols.). Disponible online en $<\mathrm{http}$ ://www.villaviciosaquienvivia. org/>

Miguel Vigil, C. (1887) Asturias monumental, epigráfica y diplomática. Datos para la Historia de la provincia, Oviedo, Imp. Hospicio Provincial.

Miguel Vigil, C. (1892) Noticias biográfico-genealógicas de Pedro Menéndez de Avilés, primer adelantado y conquistador de la Florida, Avilés, Imp. La Unión.

Navia Osorio y Castropol, L. (1976) Datos para la historia del Concejo de Navia, Oviedo, Imprenta La Cruz.

Pedrayes Овaya, J. J. (1994) Villaviciosa de Asturias. Análisis urbano, Oviedo, Colegio de Arquitectos de Asturias.

Ponce de León, A. (1771) Representación contra el pretendido Voto de Santiago que hace al rey nuestro señor D. Carlos III, el Duque de Arcos, Madrid, [s.i.].

Rey Castelao, O. (1985) La historiografía del Voto de Santiago: recopilación crítica de una polémica histórica, Santiago de Compostela, Universidade de Santiago de Compostela.

Rojas Contreras, J. (1768) Historia del Colegio Viejo de San Bartholomé, Mayor de la célebre Universidad de Salamanca, Madrid, Andrés Ortega.

Sánchez Pascual, P. (2018) "Fondos notariales, concejiles y nobiliarios para el estudio de la época de Carlos V en el Principado de Asturias", Cuadernos de Historia Moderna, 43(2), 543-567.

Sandoval, P. (1846 [1614]) Historia de la vida y hechos del Emperador Carlos V, t. I, Madrid, Est. Literario-Tipográfico de P. Madoz y L. Sagasti.

Solano Fernández-Sordo, Á. (2015a) “Entre Quexales y Bustos. La rivalidad entre las élites locales en el nacimiento 
de la Puebla de Maliayo (Asturias)", Roda da Fortuna, 4(1-1), 264-299.

SOlAno Fernández-Sordo, Á. (2015b) “Algunas cosas que son neçesarias para la buena governaçión de dicha villa e conçejo. Poder concejil, gobierno urbano y conflicto social en Villaviciosa a fines de la Edad Media", en García Fernández, E. y Bonachía Hernando, J. A. (eds.), Hacienda, mercado y poder al norte de la Corona de Castilla en el tránsito del Medievo a la Modernidad, Valladolid, Castilla Ediciones, 469-500.

Solano Fernández-Sordo, Á. (2017a) “Acatando algunos servicios fechos quando aporté en la dicha villa. Los privilegios de Carlos I a Villaviciosa tras su llegada", Boletín de Letras del Real Instituto de Estudios Asturianos, 189-190, 57-78.

Solano Fernández-Sordo, Á. (2017b) Poreñu, coto y señorío. Su historia y sus documentos, Villaviciosa, Ayto. de Villaviciosa.

Solano Fernández-Sordo, Á. (2018) “Villaviciosa, 1517. El concejo que vio Carlos de Gante", en Álvarez Fernández, M. (ed.), Quinientos años después: Villaviciosa, 1517. La época en que don Carlos vino a Asturias, Oviedo: Universidad de Oviedo, 49-122.

Uría Ríu, J. (2011) “El viaje de Carlos I por Asturias”, en Uría Maqua, Juan (ed.): Obra completa, V. Edad Moderna y contemporánea, Oviedo, KRK, 31-98.

Vital, L. (1992) Primer viaje a España de Carlos I con su desembarco en Asturias, Oviedo, Grupo Editorial Asturiano. 